\title{
Monocarboxylate Transporters (SLC16): Function, Regulation, and Role in Health and Disease
}

\author{
Melanie A. Felmlee, ${ }^{1}$ Robert S. Jones, ${ }^{1}$ Vivian Rodriguez-Cruz, Kristin E. Follman, and Marilyn E. Morris \\ Department of Pharmaceutics and Medicinal Chemistry, Thomas J. Long School of Pharmacy and Health Sciences, University of the Pacific, \\ Stockton, California (M.A.F.); Department of Pharmaceutical Sciences, School of Pharmacy and Pharmaceutical Sciences, University at \\ Buffalo, State University of New York, Buffalo, New York (R.S.J., V.R.-C., M.E.M.); and Certara Strategic Consulting, Certara USA, \\ Princeton, New Jersey (K.E.F.)
}

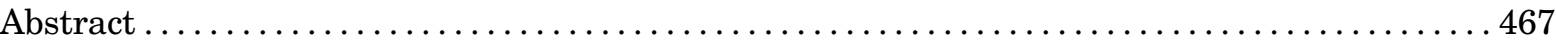

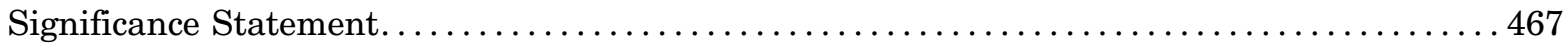

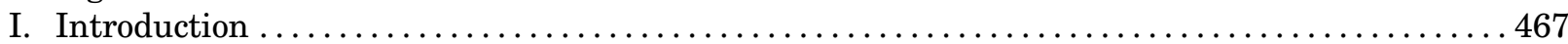

II. Structure and Function .................................................... 468

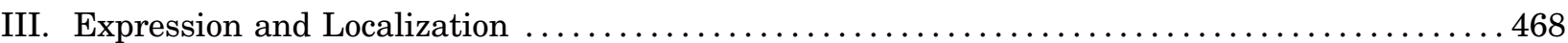

IV. Substrates and Inhibitors ............................................. 468

V. Regulation and Development............................................... 469

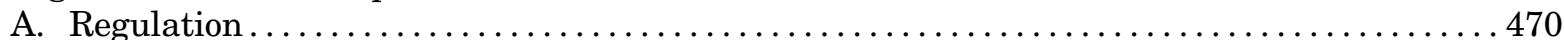

1. Transcriptional Regulation ...................................... 470

2. Epigenetic Regulation......................................... 473

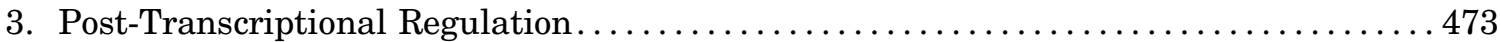

4. Membrane Trafficking Regulation .................................. 474

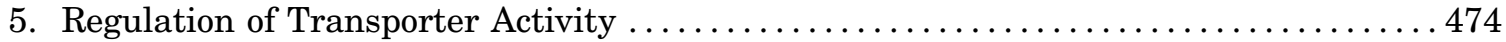

B. Sex Differences .................................................. 475

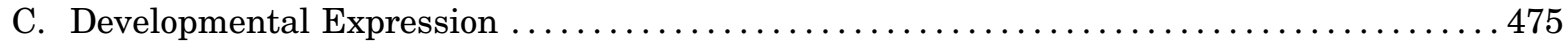

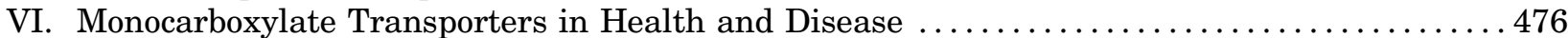

A. Monocarboxylate Transporters 1, 2, 4 (SLC16A1, SLC16A7, SLC16A3) ............. 476

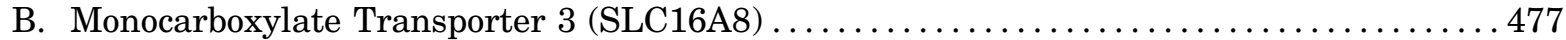

C. Monocarboxylate Transporter 5 (SLC16A4) ............................. 477

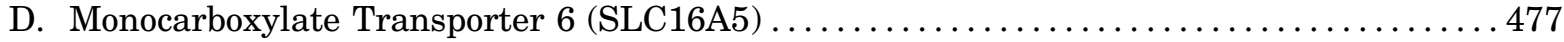

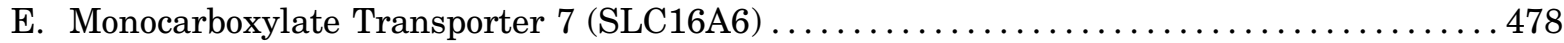

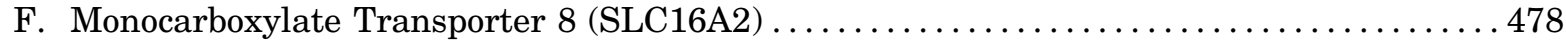

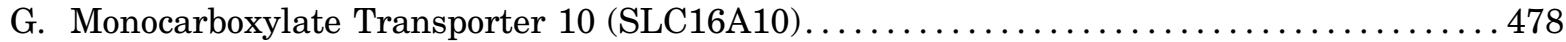

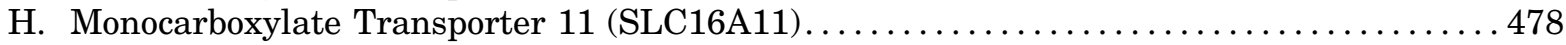

I. Monocarboxylate Transporter 12 (SLC16A12) ............................. 479

J. Monocarboxylate Transporter 13/14 (SLC16A13/16A14) ........................ 479

VII. Findings from the Use of Genetically-Modified Mct Rodent Models ................... 479

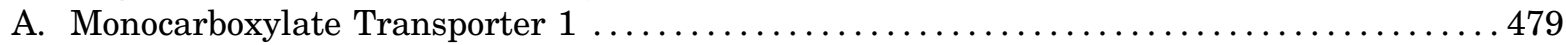

B. Monocarboxylate Transporter 2 ............................................ 479

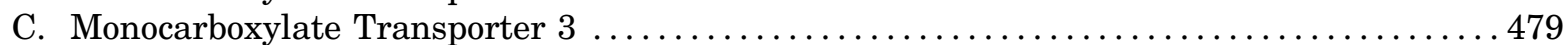

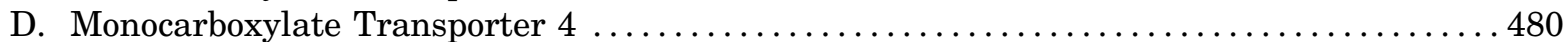

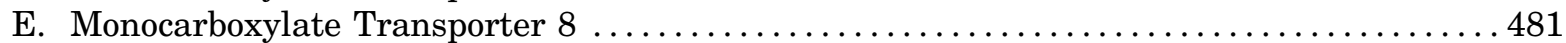

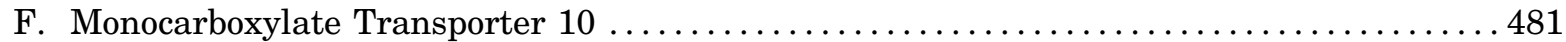

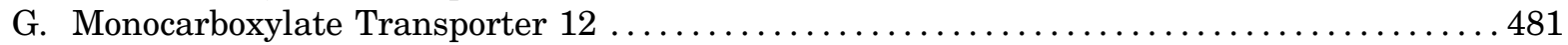

Address correspondence to: Dr. Marilyn E. Morris, Department of Pharmaceutical Sciences, University at Buffalo, State University of New York, 445 Pharmacy Building, Buffalo, NY 14214-8033. E-mail: memorris@buffalo.edu

This work was supported in part for M.E.M. by the National Institutes of Health National Institute for Drug Abuse [Grant R01- DA023223] and an IMPACT grant from the University at Buffalo. V.R.-C. was supported in part by a supplement [to Grant R01-DA023223] and a fellowship from the American Association for Pharmaceutical Education.

${ }^{1}$ M.A.F. and R.S.J. contributed equally to this work.

https://doi.org/10.1124/pr.119.018762. 
H. Other Monocarboxylate Transporter Isoforms $\ldots \ldots \ldots \ldots \ldots \ldots \ldots \ldots \ldots \ldots \ldots \ldots 1$

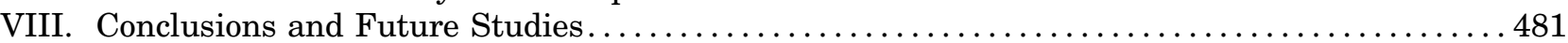

References.................................................... 482

Abstract_- The solute carrier family 16 (SLC16) is comprised of 14 members of the monocarboxylate transporter (MCT) family that play an essential role in the transport of important cell nutrients and for cellular metabolism and $\mathrm{pH}$ regulation. MCTs 1-4 have been extensively studied and are involved in the protondependent transport of $L$-lactate, pyruvate, short-chain fatty acids, and monocarboxylate drugs in a wide variety of tissues. MCTs 1 and 4 are overexpressed in a number of cancers, and current investigations have focused on transporter inhibition as a novel therapeutic strategy in cancers. MCT1 has also been used in strategies aimed at enhancing drug absorption due to its high expression in the intestine. Other MCT isoforms are less well characterized, but ongoing studies indicate that MCT6 transports xenobiotics such as bumetanide, nateglinide, and probenecid, whereas MCT7 has been characterized as a transporter of ketone bodies. MCT8 and MCT10 transport thyroid hormones, and recently, MCT9 has been characterized as a carnitine efflux transporter and MCT12 as a creatine transporter. Expressed at the blood brain barrier, MCT8 mutations have been associated with an X-linked intellectual disability, known as Allan-Herndon-Dudley syndrome. Many MCT isoforms are associated with hormone, lipid, and glucose homeostasis, and recent research has focused on their potential roles in disease, with MCTs representing promising novel therapeutic targets. This review will provide a summary of the current literature focusing on the characterization, function, and regulation of the MCT family isoforms and on their roles in drug disposition and in health and disease.

Significance Statement-The 14-member solute carrier family 16 of monocarboxylate transporters (MCTs) plays a fundamental role in maintaining intracellular concentrations of a broad range of important endogenous molecules in health and disease. MCTs 1, 2, and 4 (L-lactate transporters) are overexpressed in cancers and represent a novel therapeutic target in cancer. Recent studies have highlighted the importance of MCTs in glucose, lipid, and hormone homeostasis, including MCT8 in thyroid hormone brain uptake, MCT12 in carnitine transport, and MCT11 in type 2 diabetes.

\section{Introduction}

Monocarboxylate transporters (MCTs) are members of the solute carrier 16 (SLC16) family of transporters that are essential for the transport of short-chain monocarboxylates, hormones, nutrients, and amino acids (Price et al., 1998; Halestrap and Price, 1999; Halestrap and Meredith, 2004; Halestrap, 2013b; Jones and Morris, 2016). Due to this broad range in substrate specificity, it is evident that that these transporters play a pivotal role in the homeostasis and function of circulating endogenous molecules. In total, there are 14 isoforms within the MCT family (MCTs 1-14, SLC16A1-14), as well as two members of the sodium-dependent MCT family (SMCTs 1/2, SLC5A8/12). MCTs 1-4 are proton-dependent transporters and are well characterized due to their critical role in the transport of products of the glycolysis cycle (i.e., lactate and pyruvate), as well as ketone bodies (such as acetoacetate and $\beta$-hydroxybutyrate) across the plasma membrane. The other MCTs 5-14 have been less investigated, although recent studies have provided some information on their substrate specificities. Although not much is known regarding the substrate specificity of MCT5, MCT6 has been shown to transport drugs such as bumetanide, nateglinide, and probenecid (Murakami et al., 2005; Kohyama et al., 2013). Similar to MCTs 1-4, MCT7 transports ketone bodies (Hugo et al., 2012). MCT8 and MCT10 have been reported to transport thyroid hormones (Halestrap and Meredith, 2004), with MCT10 also being responsible for transporting aromatic amino acids. MCT9 has been characterized as a carnitine efflux transporter (Suhre et al., 2011) and MCT12 as a creatine transporter (Abplanalp et al., 2013). This review will not discuss the SMCTs that are members of the SLC5 family, namely SLC5A8 (SMCT1) and SLC5A12 (SMCT2), which have been the subject of other reviews (Ganapathy et al., 2008).

The first published investigation into this family of transporters was in the 1970s, in which Halestrap and Denton (1974) demonstrated that pyruvate transport was inhibited by $\alpha$-cyano-4-hydroxycinnamate (CHC) in rat liver mitochondria and human erythrocytes. These data were supplemented with research performed by Mowbray (1974, 1975), which discovered evidence that pyruvate was pumped across the mitochondrial membrane in rat liver, and that this transporter potentially exhibited a broad specificity toward other monocarboxylates and regulated pyruvate oxidation. Subsequently, additional investigation into these MCTs was performed by Halestrap (1976) and coworkers at the

ABBREVIATIONS: AHDS, Allan-Herndon-Dudley syndrome; AICAR, 5-aminoimidazole-4-carboxaminde-1- $\beta$-D ribofuranoside; AMPK, AMP-activated protein kinase; CARP, carbonic anhydrase-related protein; CHC, $\alpha$-cyano-4-hydroxycinnamate; CHO, Chinese hamster ovary; HIF-1 $\alpha$, hypoxia-inducible factor $1 \alpha$ subunit; MCT, monocarboxylate transporter; miRNA, microRNA; NASH, nonalcoholic steatohepatitis; $\mathrm{NF}-\kappa \mathrm{B}$, nuclear factor $\kappa$-light-chain enhancer of activated B cells; PPAR $\alpha$, peroxisome proliferator-activated receptor $\alpha$; RPE, retinal pigment epithelium; SLC, solute carrier; SMCT, sodium-dependent MCT; SNP, single-nucleotide polymorphism; T 3 , triiodothyronine; T2D, type II diabetes; TM, transmembrane; UTR, untranslated region. 
University of Bristol (Bristol, UK); Halestrap (1976) became an early pioneer in characterizing this family of transporters. Halestrap (1976) investigated the mechanism of transport in human erythrocytes, demonstrating the physiologically relevant monocarboxylate carriermediated system. Following protein sequence analysis of the isolated rabbit erythrocyte lactate transporter, cDNA for hamster MCT from Chinese hamster ovary (CHO) cells was used to isolate the gene encoding for human MCT1 (Garcia et al., 1994; Poole and Halestrap, 1994). Following this finding, the first isoform of the MCT family (MCT1) was cloned and expressed in CHO cells from rat skeletal muscle (Jackson et al., 1995), and subsequently in others species. Using expression sequence tags to identify other homologs with similar sequence identity, additional putative MCT isoforms were identified from human cDNA libraries (Price et al., 1998). Eventually, additional MCT isoforms were discovered using similar methods, transfected, and characterized over the next several decades (Halestrap and Wilson, 2012).

\section{Structure and Function}

Structurally, these MCTs share conserved amino acid identity, predicted topology, as well as homology (Halestrap, 2012). All MCT isoforms are predicted to contain 12 transmembrane (TM) domains, intracellular $\mathrm{C}$ and $\mathrm{N}$ termini, as well as a large intracellular loop between TMs 6 and 7. The most conserved regions of the MCT isoforms, similar to other solute carriers, are the membrane-spanning regions, in contrast to the TM 6-7 loop and large C-terminal tail residues (Fig. 1). A summary of the percent amino acid identity between the 14 human MCT isoforms is depicted in Table 1 . In addition, the sequence similarity among these isoforms in different species tends to depend on

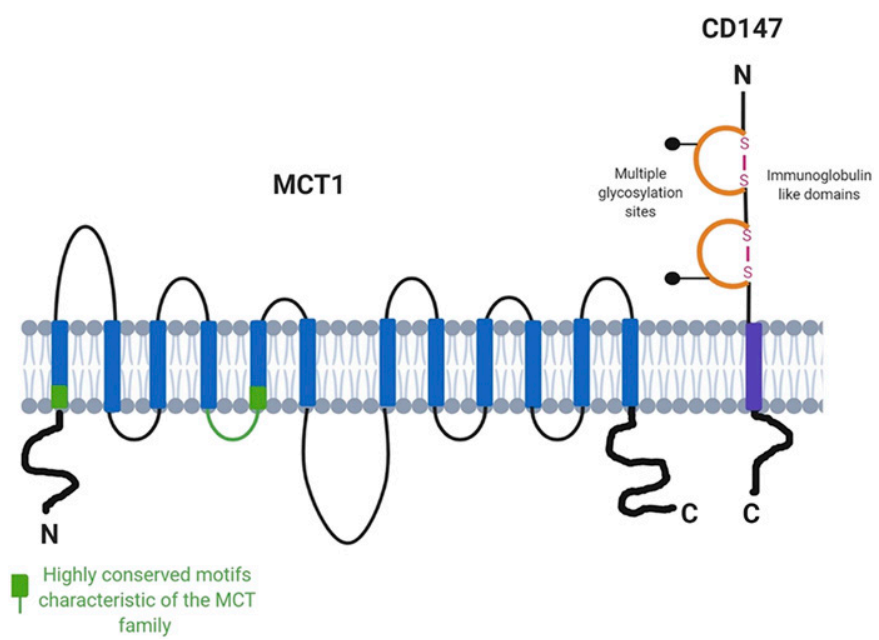

Fig. 1. The proposed topology of the MCT family members. CD147, the ancillary protein that associates with MCT1 and MCT4, is also shown. The $\mathrm{N}$ and $\mathrm{C}$ termini and the large loop between transmembrane domains 6 and 7 show the greatest variation between family members, whereas the TMDs themselves are highly conserved. Adapted from Halestrap and Meredith (2004) and Halestrap (2013a). the evolutionary relatedness of their host species. Figure 2 depicts the phylogenetic ancestry of MCTs 1-14 in humans, which shows similar patterns of evolutionary relationships across other mammalian species based on amino acid sequence. Although the MCTs demonstrate conserved sequence motifs, their differential expression, regulation, and variable amino acid residues allow for a dynamic ligand-specific and unique physiologic impact for each isoform. Additionally, MCTs have demonstrated dependencies on a variety of ancillary proteins, in order for proper trafficking and function at the plasma membrane. In particular, basigin, also known as CD-147, has been shown to interact with MCTs $1,3,4,11$, and 12 primarily through noncovalent interactions (Kirk et al., 2000; Castorino et al., 2011b; Rusu et al., 2017). In contrast, MCT2 has demonstrated preferentially to form a complex with embigin, otherwise known as gp70, a related member of the $\mathrm{Ig}$ superfamily (Wilson et al., 2005).

\section{Expression and Localization}

Tissue and cellular distribution of MCTs are detailed in Fig. 3 and Table 2 and include the species and type of expression (mRNA/protein) that has been reported. Protein expression data are lacking for MCT5, MCT7, MCT9, and MCT11-14.

\section{Substrates and Inhibitors}

Investigation of MCT1 transport initially focused on lactate, but the transporter has more varied substrates than initially thought (Morris and Felmlee, 2008). Inhibitors of MCTs 1-4 include phloretin and quercetin, amphiphilic compounds, and CHC, a bulky monocarboxylate (Morris and Felmlee, 2008). MCT8, 9, 10, and 12 are also known to transport monocarboxylates, including more hydrophobic molecules such as creatinine and carnitine (Fisel et al., 2018). MCT7 has not been extensively studied, but has been shown to transport ketone bodies, specifically $\beta$-hydroxybutyrate (Hugo et al., 2012). Transgenic expression of human MCT7 in zebrafish with endogenous MCT7 knocked down has been shown to rescue the phenotype (Hugo et al., 2012). Studies utilizing site-directed mutagenesis and homology modeling were performed to probe the substrate translocation cycle to better understand the dynamics of MCT substrate specificity (Wilson et al., 2009). These studies suggested that conserved amino acid positions (i.e., lysine 38, aspartate 302, and arginine 306) in MCT1 were required for the proposed mechanism, and that these amino acids were also present in MCTs 1, 3, and 4, which is consistent with their similar substrate profile. Seeing as MCT7 is the only other MCT isoform to contain these conserved amino acids (with the exception of glutamate instead of aspartate near the position 302), these findings 
TABLE 1

A summary of the percent amino acid identity of the human MCT isoforms (matrix was generated using Clustal Omega)

\begin{tabular}{|c|c|c|c|c|c|c|c|c|c|c|c|c|c|c|}
\hline & MCT1 & MCT2 & MCT3 & MCT4 & MCT5 & MCT6 & MCT7 & MCT8 & MCT9 & MCT10 & MCT11 & MCT12 & MCT13 & MCT14 \\
\hline MCT1 & 100 & 59.21 & 39.43 & 44.57 & 24.11 & 29.07 & 29.05 & 22.84 & 23.03 & 24.23 & 28.8 & 29.37 & 30.81 & 24.94 \\
\hline MCT2 & 59.21 & 100 & 42.77 & 46.74 & 26.39 & 32.16 & 31.61 & 24.22 & 26.88 & 24.38 & 32.05 & 29.83 & 31.83 & 27.23 \\
\hline MCT3 & 39.43 & 42.77 & 100 & 56.93 & 24.71 & 37.5 & 28.12 & 26.34 & 26.46 & 26.61 & 36.05 & 33.47 & 34.44 & 23.98 \\
\hline MCT4 & 44.57 & 46.74 & 56.93 & 100 & 25.43 & 36.81 & 31.82 & 26.68 & 28.68 & 26.33 & 32.64 & 34.85 & 30.56 & 27.95 \\
\hline MCT5 & 24.11 & 26.39 & 24.71 & 25.43 & 100 & 24.23 & 27.48 & 22.43 & 25.91 & 24.16 & 26.59 & 29.91 & 29.8 & 25.58 \\
\hline MCT6 & 29.07 & 32.16 & 37.5 & 36.81 & 24.23 & 100 & 28.57 & 24.19 & 23.94 & 23.81 & 30.32 & 30.18 & 28.43 & 24.71 \\
\hline MCT7 & 29.05 & 31.61 & 28.12 & 31.82 & 27.48 & 28.57 & 100 & 21.22 & 26.62 & 20.5 & 25.78 & 25.48 & 34.36 & 22.74 \\
\hline MCT8 & 22.84 & 24.22 & 26.34 & 26.68 & 22.43 & 24.19 & 21.22 & 100 & 25.94 & 52.17 & 26.01 & 22.43 & 23.13 & 23.68 \\
\hline МCT9 & 23.03 & 26.88 & 26.46 & 28.68 & 25.91 & 23.94 & 26.62 & 25.94 & 100 & 27.23 & 27.47 & 25.68 & 29.24 & 32.16 \\
\hline MCT10 & 24.23 & 24.38 & 26.61 & 26.33 & 24.16 & 23.81 & 20.5 & 52.17 & 27.23 & 100 & 25.84 & 23.64 & 24.28 & 26.44 \\
\hline MCT11 & 28.8 & 32.05 & 36.05 & 32.64 & 26.59 & 30.32 & 25.78 & 26.01 & 27.47 & 25.84 & 100 & 30.23 & 46.93 & 27.51 \\
\hline MCT12 & 29.37 & 29.83 & 33.47 & 34.85 & 29.91 & 30.18 & 25.48 & 22.43 & 25.68 & 23.64 & 30.23 & 100 & 33.01 & 28.57 \\
\hline MCT13 & 30.81 & 31.83 & 34.44 & 30.56 & 29.8 & 28.43 & 34.36 & 23.13 & 29.24 & 24.28 & 46.93 & 33.01 & 100 & 26.93 \\
\hline MCT14 & 24.94 & 27.23 & 23.98 & 27.95 & 25.58 & 24.71 & 22.74 & 23.68 & 32.16 & 26.44 & 27.51 & 28.57 & 26.93 & 100 \\
\hline
\end{tabular}

support the substrate similarities of MCT7 and MCTs 1-4 and their ability to transport ketone bodies. MCT5, 13, and 14 still have no known substrates and therefore remain orphan transporters. Recently, more substrates and inhibitors have been identified for MCT6, including flavonoids as inhibitors of bumetanide transport (Jones et al., 2017). Substrates and inhibitors of the MCT family members and their respective $\mathrm{K}_{\mathrm{m}}, \mathrm{K}_{\mathrm{i}}$, or $\mathrm{IC}_{50}$ values, as identified from in vitro systems, are listed in Table 3 . It should be noted that $\mathrm{K}_{\mathrm{m}}$ values for MCT1-4 are dependent on the $\mathrm{pH}$ gradient of the system, with higher $\mathrm{K}_{\mathrm{m}}$ values observed in the absence of a $\mathrm{pH}$ gradient (Morse et al., 2012).

\section{Regulation and Development}

Mechanisms demonstrated to regulate MCTs have only begun to be characterized, including the influence of biologic sex on expression and their developmental regulation. Although most studies have focused on the

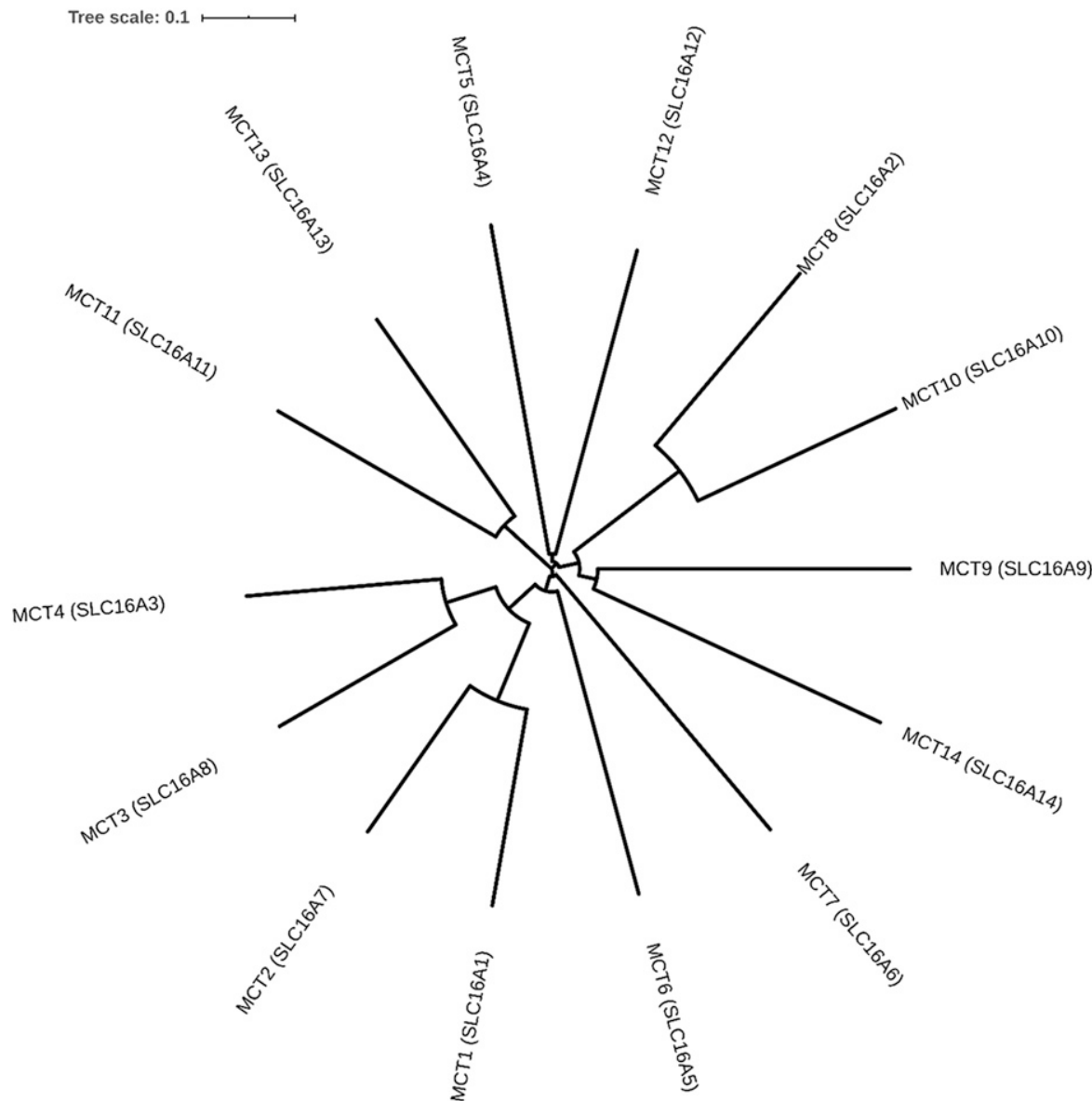

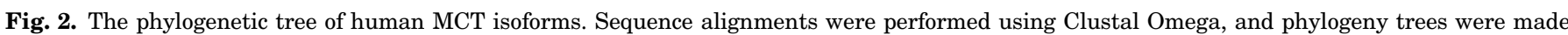

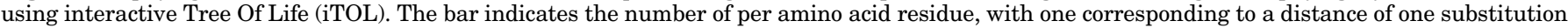
per 10 amino acid residues. Adapted from Halestrap (2012). 


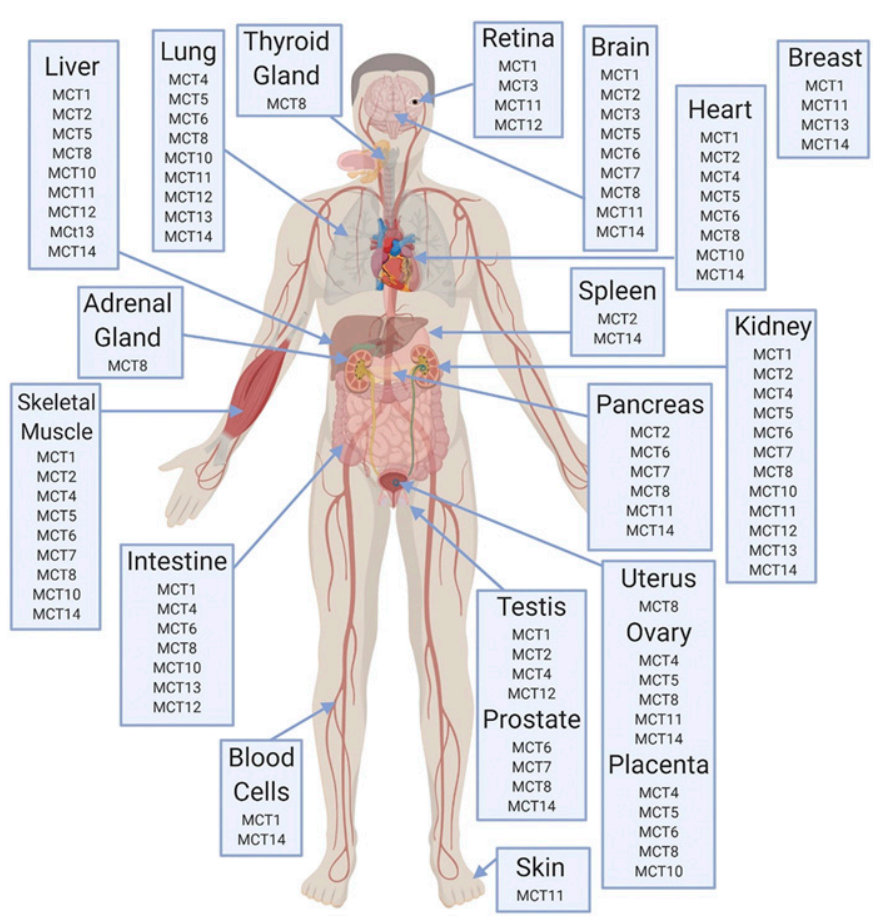

Fig. 3. Tissue protein expression of MCT isoforms in humans, based on data compiled by Morris and Felmlee (2008).

regulation of MCT1 and MCT4, this review includes available data for the other transporters.

\section{A. Regulation}

1. Transcriptional Regulation. Numerous studies have demonstrated transcriptional changes in MCTs in a range of tissues and disease states; however, there are limited studies investigating the mechanisms underlying the observed changes in mRNA expression.

The human MCT1 promoter was identified and characterized in the early 2000 s, and potential binding sites have been identified within the promoter region for a range of transcription factors, including USF1, USF2, AP1, AP2, SP1, MZF1, and nuclear factor $\kappa$-light-chain enhancer of activated B cells (NF- $\kappa$ B) (Cuff and ShiraziBeechey, 2002; Hadjiagapiou et al., 2005). The human MCT1 promoter contains USF1 and 2 binding sites that functionally repress MCT1 transcription in human intestinal Caco-2 cells, whereas the distal SP1 site stimulates promoter activity (Hadjiagapiou et al., 2005). NF- $\kappa \mathrm{B}$ inhibitors reverse the stimulatory effect of butyrate on MCT1 promoter activity in human adenoma-derived (AA/C1) cells, suggesting that the NF- $\kappa \mathrm{B}$ pathway is involved in MCT1 transcriptional regulation (Borthakur et al., 2008). AP2 overexpression in Caco-2 cells increases MCT1 promoter activity, and site-directed mutagenesis of the AP2 binding site results in decreased transcription in response to phorbol 12-myristate 13-acetate, supporting the role of phosphokinase C-dependent AP2 transcriptional regulation of MCT1 (Saksena et al., 2009). The peroxisome proliferator-activated receptor $\alpha(\operatorname{PPAR} \alpha)$ agonist WY 14,643 upregulates MCT1 mRNA expression in the liver, kidney, and small intestine, and this upregulation is absent in PPAR $\alpha$ null mice (König et al., 2008). A putative PPAR $\alpha$ response element was identified in the mouse promoter (König et al., 2008), and expression was induced in the presence of clofibrate and natural PPAR $\alpha$ agonists (König et al., 2010). Skeletal muscle expression of MCT1 mRNA and protein expression are upregulated by exercise and 5 -aminoimidazole-4-carboxaminde-1- $\beta$-D ribofuranoside (AICAR) treatment, which activate AMPactivated protein kinase (AMPK) in rats (Furugen et al., 2011; Kitaoka et al., 2011b, 2014; Takimoto et al., 2013). This stimulation is muscle-type specific, with MCT1 expression increases in white gastrocnemius, plantaris, and tricep muscle (Furugen et al., 2011; Kitaoka et al., 2011b, 2014; Takimoto et al., 2013). Additionally, upregulation of MCT1, MCT2, and MCT4 mRNA expression was observed in swine containing a gain-of-function mutation in the AMPK gene (England et al., 2017). MCT1 mRNA and protein expression are upregulated by c-Myc in P493-6 B-lymphoma cells through direct binding of c-Myc to the MCT1 promoter region (Doherty et al., 2014). Overexpression of the transcription factor metastasis-associated in colon cancer1 increases MCT1 protein expression in gastric cancer cell lines, whereas its silencing decreases MCT1 expression (Wang et al., 2017). In human colon cancer NCM460 and HCT15 cells, MCT1 mRNA and protein expression increases with increasing expression of the transcription factor Nrf2 (Diehl et al., 2018). Treatment with small interfering RNA against Nrf2 in NCM460 cells decreases MCT1 expression, confirming the role of Nrf2 in MCT1 regulation in the colon (Diehl et al., 2018); however, whether Nrf2 binds to the MCT1 promoter region was not evaluated.

Studies assessing transcriptional regulation for MCT4 are limited. Nrf2 and c-Myc transcriptionally regulate MCT1, but not MCT4 (Doherty et al., 2014; Diehl et al., 2018). Hypoxia induces MCT4 mRNA expression, and site-directed mutagenesis of the MCT4 promotor demonstrates that hypoxia-inducible factor $1 \alpha$ subunit (HIF$1 \alpha$ ) binding mediated the observed upregulation (Ullah et al., 2006). Furthermore, this upregulation was not observed in CHO cells lacking HIF-1 $\alpha$ (Ullah et al., 2006). Additionally, HIF- $1 \alpha$ upregulates MCT4 mRNA expression in mouse endothelial cells in response to nitric oxide treatment (Brix et al., 2012). HIF- $1 \alpha$ small interfering RNA treatment of human rhabdomyosarcoma cells decreases MCT4 mRNA and protein expression (Narumi et al., 2012). Functional analysis of the MCT4 promoter showed that hypoxia-response elements within the promoter were critical to the HIF$1 \alpha$-mediated activation of MCT4 transcription (Narumi et al., 2012). AMPK activation through AICAR treatment stimulates MCT4 mRNA, and protein expression is white gastrocnemius and planteris muscle, but not in other skeletal muscle types (Furugen et al., 2011; Kitaoka et al., 2011b). AMPK is stimulated during exercise with 
TABLE 2

Tissue and subcellular distribution of monocarboxylate transporters

\begin{tabular}{|c|c|c|c|c|c|c|}
\hline Transporter & $\begin{array}{l}\text { Unigene } \\
\text { Name }\end{array}$ & Tissue Distribution & Subcellular Localization & Expression & Species & References \\
\hline MCT1 & SLC16A1 & Ubiquitous & $\begin{array}{l}\text { Apical and basolateral } \\
\text { membrane }\end{array}$ & & Human & Halestrap and Meredith, 2004; Gill et al., 2005 \\
\hline \multirow[t]{8}{*}{ MCT2 } & \multirow[t]{8}{*}{ SLC16A7 } & Liver & Basolateral membrane & Protein & Human & \multirow{8}{*}{$\begin{array}{l}\text { Garcia et al., 1994; Lin et al., 1998; Halestrap } \\
\text { and Meredith, 2004; Wilson et al., 2005; } \\
\text { Becker et al., 2010b }\end{array}$} \\
\hline & & Kidney & $\begin{array}{l}\text { Basolateral membrane } \\
\text { Apical }\end{array}$ & Protein & $\begin{array}{l}\text { Human } \\
\text { Mouse }\end{array}$ & \\
\hline & & Skeletal muscle & & Protein & Human & \\
\hline & & Heart & & Protein & Human & \\
\hline & & Brain & & Protein & Human & \\
\hline & & Spleen & & Protein & Human & \\
\hline & & Testis & Basolateral membrane & Protein & Human & \\
\hline & & Pancreas & & Protein & Human & \\
\hline MCT3 & SLC16A8 & $\begin{array}{l}\text { Retinal pigment } \\
\text { epithelium }\end{array}$ & Basolateral membrane & & & Halestrap and Meredith, 2004 \\
\hline \multirow[t]{5}{*}{ MCT4 } & \multirow[t]{5}{*}{ SLC16A3 } & Kidney & Basolateral membrane & Protein & Human & \multirow{5}{*}{$\begin{array}{l}\text { Dimmer et al., 2000; Halestrap and Meredith, } \\
\text { 2004; Settle et al., 2004; Gill et al., 2005; } \\
\text { Wang et al., 2006b }\end{array}$} \\
\hline & & Skeletal muscle & & Protein & Human & \\
\hline & & Intestine & Basolateral membrane & Protein & Human & \\
\hline & & Heart & & Protein & Human & \\
\hline & & Lung & & Protein & Human & \\
\hline \multirow[t]{2}{*}{ MCT5 } & \multirow[t]{2}{*}{ SLC16A4 } & Liver & & mRNA & Rat & \multirow[t]{2}{*}{ Felmlee } \\
\hline & & Kidney & & mRNA & Rat & \\
\hline \multirow[t]{2}{*}{ MCT6 } & \multirow[t]{2}{*}{ SLC16A5 } & Kidney & & mRNA & Rat & \multirow{4}{*}{$\begin{array}{l}\text { Felmee } \\
\text { Gill et al., } 2005 \\
\text { Felmlee } \\
\text { Bonen et al., 2006; Nishimura and Naito, 2008; } \\
\quad \text { Roberts et al., 2008 }\end{array}$} \\
\hline & & Intestine & Basolateral membrane & Protein & Human & \\
\hline MCT7 & SLC16A6 & Kidney & & mRNA & Rat & \\
\hline \multirow[t]{12}{*}{ MCT8 } & \multirow[t]{12}{*}{ SLC16A2 } & Liver & Sinusoidal membrane & mRNA & $\begin{array}{l}\text { Human, } \\
\text { Rat }\end{array}$ & \\
\hline & & Kidney & $\begin{array}{l}\text { Basolateral membrane } \\
\text { (proximal tubule) }\end{array}$ & mRNA & $\begin{array}{l}\text { Human, } \\
\text { Rat }\end{array}$ & \multirow[t]{11}{*}{ Felmlee } \\
\hline & & Adrenal gland & & mRNA & Human & \\
\hline & & $\begin{array}{l}\text { Brain (neurons, blood } \\
\quad \text { brain barrier) }\end{array}$ & & mRNA & Human & \\
\hline & & Choroid plexus & Apical membrane & Protein & $\begin{array}{l}\text { Human } \\
\text { Mouse }\end{array}$ & \\
\hline & & Ovary & & mRNA & Human & \\
\hline & & Thyroid gland & & mRNA & Human & \\
\hline & & Uterus & & mRNA & Human & \\
\hline & & Placenta & & mRNA & Human & \\
\hline & & Heart & & mRNA & Human & \\
\hline & & & & Protein & Rat & \\
\hline & & Lung & & mRNA & Rat & \\
\hline \multirow[t]{4}{*}{ MCT10 } & \multirow[t]{4}{*}{ SLC16A10 } & Liver & & mRNA & Rat & \multirow[t]{4}{*}{ Felmlee } \\
\hline & & Kidney & & mRNA & Rat & \\
\hline & & Intestine & & mRNA & Rat & \\
\hline & & Lung & & mRNA & Rat & \\
\hline \multirow[t]{3}{*}{ MCT11 } & \multirow[t]{3}{*}{ SLC16A11 } & Liver & & mRNA & Rat & \multirow[t]{3}{*}{ Felmlee } \\
\hline & & Kidney & & mRNA & Rat & \\
\hline & & Lung & & mRNA & Rat & \\
\hline MCT12 & SLC16A12 & Liver & & mRNA & Rat & Felmlee \\
\hline & & Kidney & & mRNA & Rat & \\
\hline & & Lung & & mRNA & Rat & \\
\hline MCT13 & SLC16A13 & Liver & & mRNA & Rat & Felmlee \\
\hline & & Kidney & & mRNA & Rat & \\
\hline & & Intestine & & mRNA & Rat & \\
\hline & & Lung & & mRNA & Rat & \\
\hline MCT14 & SLC16A14 & $\begin{array}{l}\text { Peripheral blood } \\
\text { mononuclear cells }\end{array}$ & & mRNA & Human & Banerjee et al., 2017 \\
\hline & & Kidney & & mRNA & Rat & Felmlee \\
\hline
\end{tabular}

a concomitant increase in MCT4 mRNA expression; consistent with AICAR induction, the increases in MCT4 expression were muscle-type specific (Takimoto et al., 2013). As the major isoform presents in highly glycolytic tissues such as white muscle, the upregulation of MCT4 in response to hypoxia prevents the loss of pyruvate from the cell due to the lower affinity (higher $\mathrm{K}_{\mathrm{m}}$ ) of MCT4 for pyruvate (Draoui and Feron, 2011). Alternatively, if MCT4 was not upregulated, the loss of pyruvate, rather than lactate, would result in intracellular accumulation of $\mathrm{NADH}$, which would effectively inhibit the glycolysis pathway. In the liver, MCT4 protein expression increases in response to arsenite treatment through an HIF- $1 \alpha$ and hypoxia-response element-dependent mechanism (Luo et al., 2017).

There is very limited information on the transcriptional regulation of other MCTs. MCT9 mRNA expression increases in human umbilical vein endothelial cells in response to tumor necrosis factor- $\alpha$ treatment, which is known to influence NF- $\kappa$ B pathways (Knyazev et al., 2018); however, promoter analysis was not conducted to determine whether the MCT9 promoter contained putative transcription factor binding sites. PPAR $\alpha$ agonists upregulate MCT13 mRNA expression in the 
TABLE 3

Substrates and inhibitors of monocarboxylate transporters

$\mathrm{Km}, \mathrm{Ki}$, and $\mathrm{IC}_{50}$ values were obtained from the listed references and Morris and Felmlee (2008).

\begin{tabular}{|c|c|c|c|c|c|c|c|}
\hline Isoform & Species & Expression System & Substrate & $\underset{(\mathrm{mM})}{\mathrm{Km}}$ & Inhibitor & $\underset{(\mu \mathrm{M})}{\mathrm{Ki} \text { or } \mathrm{IC}_{50}}$ & References \\
\hline \multirow[t]{13}{*}{ MCT1 } & Human & Caco-2 & Hesperetin & NA & & & Shen et al., 2015 \\
\hline & & Xenopus oocytes & Lactate & $3.5-6$ & Phloretin & $28^{a}$ & Bröer et al., 1998; Lin et al., 1998; \\
\hline & & & Pyruvate & $1.8-2.5$ & Quercetin & NA & Juel and Halestrap, 1999; Cuff \\
\hline & & & $\alpha$-Ketoisovalerate & 1.3 & $\mathrm{CHC}$ & $425^{a}$ & et al., 2002; Cundy et al., 2004; \\
\hline & & & $\alpha$-Oxoisohexanoate & 0.67 & pCMBS & NA & Nancolas et al., 2016; Curtis \\
\hline & & & $\alpha$-Oxoisovalerate & 1.25 & XP13512 & $0.62^{b}$ & et al., 2017 \\
\hline & & & Butyrate & 9 & Lonidamine & $36.8^{a}$ & \\
\hline & & & XP13512 & 0.22 & & & \\
\hline & & Jurkat membranes & & & AZD3965 & $0.0016^{a}$ & \\
\hline & Rat & MDA-MB231 & GHB & 4.6 & Phloretin & $28^{b}$ & Bröer et al., 1998, 1999; Wang et al., \\
\hline & & Xenopus oocytes & Lactate & 3.5 & Quercetin & $14^{b}$ & $2006 \mathrm{a}$ \\
\hline & & & GHB & 4.6 & Benzobromaron & $22^{b}$ & \\
\hline & & & & & $\mathrm{CHC}$ & & \\
\hline \multirow[t]{9}{*}{ MCT2 } & Human & Xenopus oocytes & Pyruvate & 0.025 & $\mathrm{CHC}$ & NA & Lin et al., 1998; Nancolas et al., \\
\hline & & & & & L-Lactate & NA & 2016 \\
\hline & & & & & GHB & NA & \\
\hline & & & & & Lonidamine & $36.4^{a}$ & \\
\hline & Rat & Xenopus oocytes & Lactate & 0.74 & Phloretin & $14^{b}$ & Broer et al., 1999; Curtis et al., 2017 \\
\hline & & & Pyruvate & NA & Quercetin & $5^{b}$ & \\
\hline & & & & & Benzobromaron & $9^{b}$ & \\
\hline & & & & & $\mathrm{CHC}$ & $24^{b}$ & \\
\hline & & $\begin{array}{l}\text { Recombinant MCT2- } \\
\text { expressing yeast } \\
\text { membranes }\end{array}$ & & & AZD3965 & $0.020^{a}$ & \\
\hline MCT3 & Human & ARPE-19 cells & Lactate & NA & & & Philp et al., 2003 \\
\hline \multirow[t]{14}{*}{ MCT4 } & Human & Xenopus oocytes & L-lactate & 28 & pCMBS & $21^{a}$ & Manning Fox et al., 2000; \\
\hline & & & D-lactate & 519 & $\mathrm{CHC}$ & $991^{a}$ & Kobayashi et al., 2006; Nancolas \\
\hline & & & Pyruvate & 153 & Phloretin & $41^{a}$ & et al., 2016 \\
\hline & & & D- $\beta$-hydroxybutyrate & 130 & NPPB & $240^{a}$ & \\
\hline & & & Acetoacetate & 216 & Fluvastatin & $32^{b}$ & \\
\hline & & & $\alpha$-Ketobutyrate & 57 & Atorvastatin & $32^{b}$ & \\
\hline & & & $\alpha$-Ketoisocaproate & 95 & Lovastatin & $44^{b}$ & \\
\hline & & & $\alpha$-Ketoisovalerate & 113 & Simvastatin & $\begin{array}{l}44 \\
79^{b}\end{array}$ & \\
\hline & & & & & Lonidamine & $40.4^{a}$ & \\
\hline & Rat & Xenopus oocytes & L-lactate & 34 & $\mathrm{CHC}$ & $350^{b}$ & Dimmer et al., 2000 \\
\hline & & & Pyruvate & 36 & pCMBS & NA & \\
\hline & & & 2-Oxoisohexanoate & 13 & & & \\
\hline & & & Acetoacetate & 31 & & & \\
\hline & & & $\beta$-Hydroxybutyrate & 65 & & & \\
\hline MCT5 & & & Unknown & & & & \\
\hline \multirow[t]{12}{*}{ MCT6 } & Human & Xenopus oocytes & Bumetanide & 0.084 & Furosemide & $46^{b}$ & Murakami et al., 2005; Kohyama \\
\hline & & & Nateglinide & 0.046 & Azosemide & $21^{b}$ & et al., 2013 \\
\hline & & & Prostaglandin $\mathrm{F}_{2} \alpha$ & NA & Piretanide & $163^{b}$ & \\
\hline & & & Probenecid & NA & Torasemide & $13^{b}$ & \\
\hline & & & & & Thiazides & NA & \\
\hline & & & & & Probenecid & NA & \\
\hline & & & & & Glibenclamide & NA & \\
\hline & & & & & Nateglinide & $5.4^{a}$ & \\
\hline & & & & & Quercetin & $25^{b}$ & Jones et al., 2017 \\
\hline & & & & & Luteolin & NA & \\
\hline & & & & & Phloretin & $23^{a}, 17^{b}$ & \\
\hline & & & & & Morin & $33^{b}$ & \\
\hline \multirow[t]{2}{*}{ MCT7 } & Human & & Ketone bodies & NA & & & Hugo et al., 2012 \\
\hline & Zebrafish & & ( $\beta$-hydroxybutyrate) & NA & & & \\
\hline \multirow[t]{4}{*}{ MCT8 } & Human & COS1 and JEG3 & $\mathrm{T}_{3}$ & NA & & & Friesema et al., 2006 \\
\hline & & cells & $\mathrm{T}_{4}$ & NA & & & \\
\hline & Rat & Xenopus oocytes & $\mathrm{T}_{3}$ & NA & N-bromoacetyl- $\mathrm{T}_{3}$ & NA & Friesema et al., 2003 \\
\hline & & & $\mathrm{T}_{4}$ & NA & Bromosulfophthalein & NA & \\
\hline МCT9 & & & Carnitine & NA & & & Jones and Morris, 2016 \\
\hline \multirow[t]{4}{*}{ MCT10 } & Rat & Xenopus oocytes & L-Trytophan & 3.8 & & & Kim et al., 2001 \\
\hline & & & L-Tyrosine & 2.6 & & & \\
\hline & & & L-Phenylalanine & 7.0 & & & \\
\hline & & & L-DOPA & 6.4 & & & \\
\hline MCT11 & & & Unknown & & & & Jones and Morris, 2016 \\
\hline \multirow{2}{*}{ MCT12 } & Human & Xenopus oocytes & Creatinine & 0.57 & & & Abplanalp et al., 2013 \\
\hline & Rat & & Creatinine & NA & & & Abplanalp et al., 2013 \\
\hline MCT13 & & & Unknown & & & & Jones and Morris, 2016 \\
\hline MCT14 & & & Unknown & & & & Jones and Morris, 2016 \\
\hline
\end{tabular}

CHC, $\alpha$-cyano-4-hydroxycinnamate; GHB, gamma-hydroxybutyric acid; NA, not available; NPPB, 5-nitro-2-(3-phenylpropylamino)benzoic acid; pCMBS, p-chloromercuribenzene sulfonate.

${ }^{a} \mathrm{Ki}$.

${ }^{b} \mathrm{IC}_{50}$. 
mouse small intestine, and this upregulation was absent in PPAR $\alpha$ null mice (Hirai et al., 2007). Yet, it is unclear whether PPAR $\alpha$ interacts directly with the MCT13 promoter or through an indirect mechanism.

2. Epigenetic Regulation. DNA methylation is a critical epigenetic process, which involves the addition of a methyl group to cytosine adjacent to guanidine $(\mathrm{CpG}$ dinucleotides). Alterations in DNA methylation status within a gene can lead to differences in gene transcription and mRNA expression levels without changing the nucleotide sequence. Although hypermethylation is associated with gene silencing, hypomethylation is associated with activation of gene expression. A number of MCTs have been reported to have $\mathrm{CpG}$ islands (short DNA sequences with an increased frequency of $\mathrm{CpG}$ dinucleotides) within their gene sequence. The majority of studies evaluating DNA methylation as a mechanism of MCT regulation focus on aberrant methylation patterns in disease states; however, DNA methylation may also play a role in tissue differences in MCT expression, such as silencing gene expression in certain tissues.

Methylation of the MCT1 promoter region downregulates MCT1 mRNA expression in MDA-MD-231 cells (human breast cancer), with demethylation (via 5aza-2'-deoxycytidine treatment) leading to increased mRNA expression (Asada et al., 2003). In contrast, methylation of MCT1 was not involved in gene silencing in the $\beta$ cells of the pancreas (Pullen et al., 2011). Methylation was evaluated in schizophrenia and bipolar disorder, and MCT2 mRNA expression correlated to DNA methylation status of CpG pairs and differed between healthy and psychotic individuals (Chen et al., 2014). MCT3 mRNA and protein expression inversely correlated with methylation of a $\mathrm{CpG}$ island within exon 2 in smooth muscle cells and aorta (Zhu et al., 2005). Furthermore, $\mathrm{CpG}$ methylation increased with disease severity, with the highest methylation (80\%) observed in aortas with severe atherosclerosis corresponding to decreased MCT3 expression (Zhu et al., 2005). Consistent with the MCT3 data, MCT4 expression (mRNA and protein) was inversely correlated with promoter DNA methylation in clear cell renal carcinoma, with increased MCT4 expression and hypomethylation correlating with decreased survival (Fisel et al., 2013, 2015). MCT6 mRNA expression was altered in response to global hypomethylation in endometrial stromal cells, suggesting that DNA methylation represents a regulatory mechanism for MCT6 expression (Hsiao et al., 2015); however, the methylation status of the MCT6 gene was not directly assessed. Interestingly, MCT11 (an orphan transporter whose function is unknown) demonstrated an inverse relationship between DNA methylation at three $\mathrm{CpG}$ sites and mRNA expression in clear-cell ovarian cancer (Cicek et al., 2013). Additional data are needed to identify how specific changes in DNA methylation patterns result in altered regulation of MCTs through transcriptional regulation mechanisms.
3. Post-Transcriptional Regulation. The lack of correlation between tissue mRNA and protein expression patterns of MCTs in a range of tissues strongly suggests the involvement of post-transcriptional regulation mechanisms. These regulation mechanisms likely involve control of protein translation, and may be related to specific sequences in the $5^{\prime}$ and $3^{\prime}$ untranslated regions (UTRs). Post-transcriptional regulation of MCT1 during the cell cycle may relate to eukaryotic translation initiation factor $4 \mathrm{E}$ and its phosphorylation state (Halestrap and Wilson, 2012); however, studies directly assessing the role of eukaryotic translation initiation factor $4 \mathrm{E}$ have not been published in the literature.

Evidence for the post-transcriptional regulation of MCTs via microRNA (miRNA) has been increasing in the past decade. miRNA bind to mRNA in a sequencespecific manner, leading to degradation of the mRNA transcript. Li et al. (2009) demonstrated that miR-124 binds to the 3'UTR of MCT1, leading to a decrease in protein expression; however, they did not observe a direct correlation between miR-124 expression and MCT1 protein expression in medulloblastoma. Furthermore, they identified binding sites for additional miRNAs (miR-9*, -29b, -183, -320, and -377) in the 3'UTR that may explain the lack of correlation that was observed in medulloblastoma ( $\mathrm{Li}$ et al., 2009). miR-124 binds to the 3'UTR of mouse and human MCT1 and downregulates endogenous MCT1 protein expression in a mouse hepatoma cell line (Pullen et al., 2011). In addition, miR-29a and -29b bind to the $3^{\prime}$ UTR of mouse and human MCT1 and downregulate endogenous MCT1 protein expression; however, they decreased protein expression to a lesser extent than miR-124 (Pullen et al., 2011). miR-29a and -29b are expressed in mouse pancreatic islets, which have no miR-124 expression, and are likely responsible for MCT1 silencing in these cells (Pullen et al., 2011). miR-495 binds to the 3'UTR of human MCT1, downregulating both mRNA and protein expression of MCT1 in HeLa cells (Liang et al., 2015). Additionally, MCT1 mRNA expression negatively correlated with miR-146a-5p in healthy human colonic mucosa and patients with ulcerative colitis, with the lowest MCT1 expression observed in inflamed ulcerative colitis biopsy specimens (Erdmann et al., 2019); however, the study did not directly evaluate miR-146a-5p binding to MCT1 mRNA.

Although the majority of studies have evaluated miRNA-mediated regulation of MCT1, a few studies have identified miRNAs that regulate MCT4 and MCT8. Xu et al. (2017) demonstrated that miR-1 mimics and inhibitors altered the mRNA and protein expression of MCT4; however, the MCT4 3'UTR was not a direct target for miR-1, suggesting that this miRNA indirectly regulates MCT4 expression possibly through regulation of HIF- $1 \alpha$ (Xu et al., 2017). mRNA expression of MCT8 was decreased in medullary thyroid carcinoma with a concomitant increase in 
miR-375 (Hudson et al., 2013); however, studies assessing whether miR-375 directly binds to the MCT8 3'UTR have not been conducted. Future studies need to focus on tissue-specific regulation of MCTs by miRNA, as this may be one of the underlying mechanisms contributing to tissue differences in MCT expression.

4. Membrane Trafficking Regulation. As previously stated, ancillary proteins are essential for trafficking MCT1-4 to the plasma membrane, and, in their absence, the transporters accumulate within the cell (Kirk et al., 2000; Wilson et al., 2005; Nakai et al., 2006). Two proteins act as chaperones facilitating membrane trafficking of MCT1-4: CD147 (basigin) and embigin (gp70) (Poole and Halestrap, 1997; Wilson et al., 2005). The association of MCTs and the ancillary proteins is necessary for transport activity, and interactions with the ancillary proteins may lead to inhibition of transporter function (Halestrap, 2013a).

MCT1, MCT3, and MCT4 preferentially bind and colocalize with CD147 in tissues (Philp et al., 2003; Halestrap, 2013b). Colocalization of MCT1/MCT4 with CD147 was confirmed by coimmunoprecipitation and fluorescence resonance energy transfer (FRET) analysis (Kirk et al., 2000; Wilson et al., 2002). A strong positive correlation between MCT1/4 and CD147 expression was seen in rat liver; however, this was not a 1:1 correlation as CD147 is involved in the membrane expression of other proteins (Cao et al., 2017). In CD147 knockout mice, MCT1, MCT3, and MCT4 expression was not present in the retinal pigment epithelia, resulting in blindness (Hori et al., 2000; Philp et al., 2003), further supporting the role of CD147 as a chaperone for MCT1, MCT3, and MCT4 membrane expression. In polarized cells in the kidney and retinal epithelia, the interaction between MCT1 and CD147 is involved in the targeting of both proteins to the apical membrane (Deora et al., 2005), whereas MCT3 and MCT4 contain basolateral sorting sequences within their $\mathrm{C}$ termini (Castorino et al., 2011a).

Additionally, CD147 regulates membrane trafficking of MCT11 and MCT12. In MCT11-transfected HEK293 cells, plasma membrane expression was regulated by CD147 expression, with knockdown of CD147 leading to significantly reduced plasma membrane MCT11 (Rusu et al., 2017). The direct interaction of MCT11 and CD147 was confirmed with coimmunoprecipitation (Rusu et al., 2017). CD147 colocalized with MCT12 in MCT12transfected HEK293 cells, and their association was verified utilizing coimmunoprecipitation (Castorino et al., 2011b). Furthermore, a single-nucleotide polymorphism (SNP) in exon 6 (c.643C $>$ T) led to decreased cell surface expression of MCT12, indicating that MCT12 requires CD147 for cell surface expression (Castorino et al., 2011b).

Embigin acts as a chaperone for MCT1 in the absence of CD147 (Wilson et al., 2005). In contrast, embigin has not been demonstrated to function as a chaperone for
MCT3 and MCT4 (Halestrap, 2013b). Embigin is required for MCT2 trafficking to the plasma membrane, and colocalization was confirmed through FRET analysis (Wilson et al., 2005; Ovens et al., 2010).

Neuroplastin functions as an ancillary protein for MCT2; knockdown of neuroplastin in Xenopus oocytes leads to decreased cell surface expression of MCT2 (Wilson et al., 2013). Additionally, neuroplastin and MCT2 are colocalized on the plasma membrane in rat cerebellum, suggesting that neuroplastin plays a role in cell surface expression of MCT2 (Wilson et al., 2013).

MCTs 5-10, 13, and 14 have not been demonstrated to require CD147 or embigin to facilitate trafficking to the plasma membrane, and no ancillary proteins have currently been identified that regulate their membrane trafficking.

5. Regulation of Transporter Activity. Although ancillary proteins are involved in MCT membrane trafficking, intra- and extracellular carbonic anhydrases influence MCT activity at the plasma membrane. This interaction was first identified by Becker et al. (2005), who demonstrated that MCT1 transport activity was enhanced by the intracellular interaction with carbonic anhydrase II (Becker et al., 2005). The increase in MCT1 and MCT4 activity was independent of their expression and was observed in the presence of both wild-type carbonic anhydrase II and a catalytically inactive mutant (CAIIV143Y) (Becker et al., 2005, 2010a; Becker and Deitmer, 2008). In contrast, MCT2 activity is not enhanced by intracellular carbonic anhydrase II (Klier et al., 2011; Noor et al., 2015); however, MCT2 activity was augmented by extracellular membrane-bound carbonic anhydrase IV (wild-type and a catalytically inactive mutant C165Y) (Klier et al., 2011). Subsequently, MCT1 and MCT4 transport activity was increased by extracellular catalytically active and inactive carbonic anhydrase IV (Klier et al., 2014). Additionally, carbonic anhydrase IX (active and inactive) augments the activity of MCT1 and MCT4 (Jamali et al., 2015; Mboge et al., 2019). It is hypothesized that the carbonic anhydrases function as a proton-collecting antenna, thereby enhancing the activity of proton-coupled MCTs (Fig. 4).

More recent studies have investigated the mechanisms underlying the augmentation of MCT transport activity by carbonic anhydrases. Carbonic anhydrase II directly binds to the $\mathrm{C}$ terminus of MCT1 and MCT4, facilitating the observed increase in transporter activity; however, it does not bind to MCT2 consistent with its inability to augment MCT2 activity (Noor et al., 2015). Interestingly, integration of six histidines into the $\mathrm{C}$ terminus of MCT4 enhanced activity, which could be further increased by coexpression with carbonic anhydrase IV, but not carbonic anhydrase II (Noor et al., 2017). Furthermore, the increase in MCT activity due to carbonic anhydrase IV expression requires carbonic anhydrase IV to bind to the ancillary proteins, CD147 and embigin 


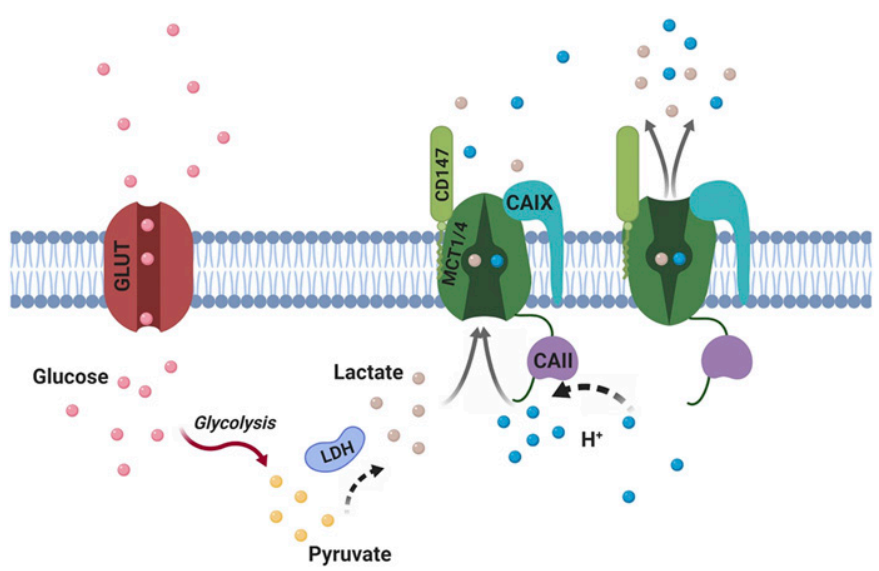

Fig. 4. The proton antenna effect of CAs in the regulation of MCT1/4. CAII/IX, carbonic anhydrase II/IX; GLUT, glucose transporter; $\mathrm{H}^{+}$, proton; LDH, lactate dehydrogenase. Adapted from Noor et al., 2018. Created with BioRender.com.

(Forero-Quintero et al., 2019). Augmentation of MCT4 transport activity by carbonic anhydrase IX requires the negatively charged carbonic anhydrase IX proteoglycanlike domain, which can function to transfer protons (Ames et al., 2018).

In addition to carbonic anhydrases, the catalytically inactive carbonic anhydrase-related proteins (CARPs) VIII, X, and XI have recently been demonstrated to enhance the transporter activity of MCT1 when coexpressed in Xenopus oocytes (Aspatwar et al., 2019). CARP VIII is an intracellular protein, whereas CARPs X and XI are secreted into the extracellular matrix, suggesting that these proteins function as intra- and extracellular proton antennas (Aspatwar et al., 2019).

\section{B. Sex Differences}

Sex differences and sex hormone-mediated regulation of MCTs are tissue-dependent, with studies focused on MCT1, MCT2, and MCT4. In rat hindlimb muscle, MCT1 and MCT4 protein expression increases in response to testosterone treatment in males; however, this induction is muscle-type specific (Enoki et al., 2006). Furthermore, MCT1 induction was not observed in heart muscle, suggesting that sex hormone-mediated regulation is tissue-specific. These results are consistent with sex differences in blood lactate level differences in humans, with males having higher plasma lactate concentrations in response to exercise (Cupeiro et al., 2012); however, a quantitative comparison of MCT1 and MCT4 expression in human muscle is lacking. In contrast to regulation in muscle, testosterone treatment decreases MCT4 mRNA and protein expression in Sertoli cells (involved in spermatogenesis) (Rato et al., 2012; Martins et al., 2013). Removal of endogenous testosterone via castration led to increased testicular MCT2 mRNA expression, which was reversed with the administration of exogenous testosterone (Boussouar et al., 2003).
MCTs are also regulated by female sex hormones in a tissue-specific manner. Hepatic MCT1 and MCT4 mRNA and protein expression varied over the estrus cycle in females rats, with females having lower expression than males (Cao et al., 2017). In ovariectomized females, hepatic MCT1 membrane expression was higher than males, whereas MCT4 expression was lower compared with males, suggesting isoform-specific regulation by female sex hormones (Cao et al., 2017). Few studies have evaluated MCT expression in response to treatment with female sex hormones. The 17- $\beta$ estradiol decreased MCT4 mRNA expression in Sertoli cells, consistent with testosterone-mediated regulation in the same cell line (Rato et al., 2012).

These studies support the involvement of both male and female sex hormones in the regulation of protondependent MCTs. Further studies are required to elucidate the role of individual sex hormones in the regulation of MCTs, as well as the underlying regulatory mechanisms.

\section{Developmental Expression}

MCT expression can be detected as early as oocyte maturation (Vannucci and Simpson, 2003), and MCT1 knockout leads to embryonic lethality, indicating its critical role in development (Lengacher et al., 2013). There is currently minimal information in the literature on developmental expression and regulation of protondependent MCTs, with most studies focused on MCT1. The available data suggest that maturation of MCTs occurs in an isoform, tissue-specific, and possibly species-dependent manner.

In humans, hepatic MCT1 membrane protein expression demonstrated a nonlinear maturation pattern with the highest expression seen in infants (Mooij et al., 2016). A subsequent study from the same group demonstrated that MCT1 membrane expression decreased after 15 weeks of age (van Groen et al., 2018); however, high variability in expression was observed in all age groups in this study, and a small sample number was used in the pediatric and adult groups. Renal MCT1 mRNA maturation in rats is consistent with these studies, with higher expression observed at earlier postnatal time points; in contrast, MCT2 mRNA expression was low at birth and increases to adult levels at sexual maturity. In the mouse brain, MCT1 and MCT2 expression peaks at postnatal day 15 , with expression levels declining rapidly until postnatal day 30 when expression levels are consistent with adult expression (Pellerin et al., 1998); however, postnatal localization of MCT1 and 2 expression in the brain is not consistent with adult localization (Baud et al., 2003). MCT1 protein expression in the rat brain (cortex, hippocampus, cerebellum, and thalamus) is consistent between 7 and 35 days old, whereas MCT2 protein expression declined with age in the cortex, cerebellum, and thalamus and increased with age in the hippocampus (Vannucci and 
Simpson, 2003). At the blood-brain barrier, MCT1 membrane expression was significantly lower in the adult cynomolgus monkey with the higher expression observed in neonates (Ito et al., 2011), which is consistent with MCT1 membrane expression in rat microvessels isolated before and after weaning (Vannucci and Simpson, 2003). In the horse, muscle MCT1 is lower at birth and increases until 2 years of age, but MCT4 expression remained the same during the 24-month study period (Kitaoka et al., 2011a). Development of muscle MCT1 and MCT4 expression is similar in rats, with lower protein expression at birth (Hatta et al., 2001). In contrast, MCT1 and MCT4 expression in the heart was highest at birth and declined over the first year of life (Hatta et al., 2001), supporting the tissuespecific regulation of MCT maturation. Renal MCT4 maturation in rats differs from what has been observed in horse muscle (Kitaoka et al., 2011a), with variable expression prior to weaning, with adult expression reached at 4 weeks old.

There is minimal information on the developmental expression of other MCTs. Expression of MCT8 was detected in the hypothalamus as early as 17 weeks gestation in humans, whereas MCT10 expression was detected at 25 weeks gestation (Friesema et al., 2012). Both MCT8 and MCT10 demonstrated nonlinear maturation patterns: strong expression was observed during early fetal development with expression levels declining at 35 weeks gestation, followed by increased expression after birth (Friesema et al., 2012).

\section{Monocarboxylate Transporters in Health and Disease}

\section{A. Monocarboxylate Transporters 1, 2, 4 (SLC16A1, SLC16A7, SLC16A3)}

The main physiologic role of MCTs 1-4 is transport of monocarboxylates, including lactate, and this contributes to the maintenance of intracellular $\mathrm{pH}$ (Halestrap, 2013b). This implicates these transporters in cancer, as tumor cells are highly glycolytic. Cancer cells with high expression of MCTs are better able to maintain an appropriate $\mathrm{pH}$ for tumor growth, therefore contributing to proliferation (Halestrap and Wilson, 2012; Pinheiro et al., 2012). The overexpression of MCT1 and MCT4 has been documented in many cancer types, including breast, bone, colon, and renal cancers (Park et al., 2018). The expression of these transporters has also been linked with worsened prognosis in many cancers, including bladder cancer (MCT1) and prostate cancer (MCT4) (Park et al., 2018). MCT2 has also been implicated as a potential biomarker in prostate cancer, selectively labeling malignant glands and improving the accuracy of diagnosis along with $\alpha$-methylacyl-CoA racemase (Pertega-Gomes et al., 2013). In addition to diagnostic purposes, the role of these transporters in cancer proliferation also has identified them as a potential target for treatment.
Recently, inhibition of MCT1 and MCT4 has been of interest for treatment of cancer due to their importance in regulating energy production in glycolytic and oxidative cancer cell metabolism, otherwise known as the Warburg Effect (shown in Fig. 5). The plasticity of cancer cells and their ability to couple these different metabolic pathways have provided support for targeting these transporters and is extensively described in the literature (Marchiq and Pouyssegur, 2016; Ždralević et al., 2018). Inhibition of MCT transport has been shown to inhibit growth in cancer cell lines (Guan et al., 2019). The development of highly potent and partially specific MCT inhibitors, such as AZD3965, has resulted in the potential for greater MCT inhibition in cancer treatment. Previously available inhibitors, such as $\mathrm{CHC}$, lack potency and specificity, making them less desirable as a therapeutic agent (Guan et al., 2019). AZD3965 is effective in reducing tumor growth and increasing intratumor lactate in small cell lung cancer cell lines (Polański et al., 2014). AZD3965 is currently in Phase I clinical trials for the treatment of diffuse large $B$ cell lymphoma and Burkitt lymphoma (Noble et al., 2017).

MCT1 exhibits ubiquitous distribution and is involved in a variety of diseases. One disease, exerciseinduced hyperinsulinemia, has been associated with mutations in MCT1. Exercise-induced hyperinsulinemia is a hypoglycemic disorder caused by mutations in the promoter region of MCT1, which results in the expression of MCT1 (Otonkoski et al., 2007). Although the activity of MCT1 is not affected in some tissues, the mutation leads to an expression of MCT1 in insulin-secreting $\beta$ cells, which allows for lactate to be oxidized during exercise and signals insulin secretion leading to hypoglycemia (Halestrap and Wilson, 2012; Halestrap, 2013b).

Recently, a common variant of MCT1 that results in differential lactate transport, and therefore differential physical performance, was reported. The missense mutation (1470T $>$ A) results in an amino acid substitution and less efficient lactate transport (Onali et al., 2018).

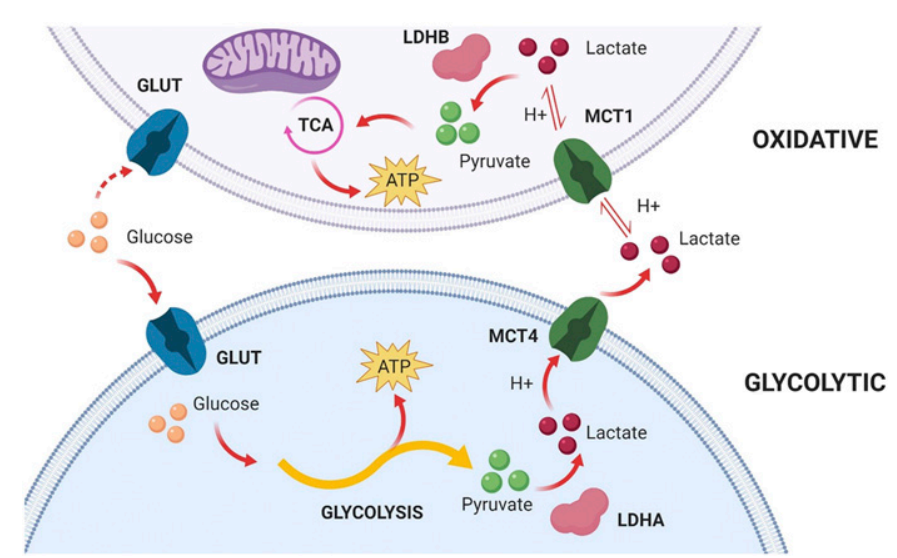

Fig. 5. A representation of the Warburg Effect by which glycolytic and oxidative cancer cells participate in lactate shuttling. GLUT, glucose transporter; $\mathrm{H}^{+}$, proton; LDHA/B, lactate dehydrogenase $\mathrm{A} / \mathrm{B}$; TCA, tricarboxylic acid cycle. Created with BioRender.com. 
The $\mathrm{T}$ allele is more common in Sub-Sarahan African groups (frequencies $86 \%-91 \%$ ) as compared with the remaining world regions (69\%-49\%) (Onali et al., 2018). The TT genotype is associated with an increased predisposition to sprint/power performances (Onali et al., 2018). A genetic variant of MCT2 has also been associated with male infertility. Two single-nucleotide polymorphisms (rs10506398 and rs10506399) were associated with increased infertility in Korean men (Jones and Morris, 2016).

MCTs may play a significant role in many metabolic diseases. For instance, in obesity, there is evidence for an increased expression of MCT4 in muscle, which decreases after weight loss (Fisel et al., 2018). In addition, it has been shown that in heterozygous knockouts of MCT1 in mice, there was a resistance to diet-induced obesity (Fisel et al., 2018). Further understanding of these mechanisms could lead to a druggable target for obesity related to MCTs. MCT1 deficiency has also been associated with recurrent ketoacidosis in children (Fisel et al., 2018). The MCT1 deficiency results in a reduced uptake of ketone bodies, contributing to acid-base imbalance (Fisel et al., 2018). It is suspected that patients are heterozygous for the MCT1 mutation and that symptoms are brought on by unknown triggers (Fisel et al., 2018).

\section{B. Monocarboxylate Transporter 3 (SLC16A8)}

MCT3 also regulates lactate transport; it does this specifically in the basolateral membrane of the retinal pigment epithelium (RPE), where it is preferentially expressed (Gallagher-Colombo et al., 2010). The retina is highly metabolically active and produces large amounts of lactate, which are transported through the RPE via MCT1, 3, and 4 (Gallagher-Colombo et al., 2010). It has been demonstrated in chick RPE/choroid explant cultures and human fetal RPE monolayers that wounding of the retina causes alterations in the expression of MCTs in the RPE. After tissue damage, there is a decrease in expression of MCT3 and an increase in the expression of MCT4 (Gallagher-Colombo et al., 2010). The return of expression of MCT3 appeared to be dependent on cell-cell contact as well as the composition of the basement membrane (Gallagher-Colombo et al., 2010). This may indicate that cell-cell contact is crucial in maintaining the differentiation of the RPE.

\section{Monocarboxylate Transporter 5 (SLC16A4)}

Currently, there is no experimental evidence for the substrate specificity of MCT5. Regarding its expression, Gill et al. (2005) demonstrated that MCT5 (which was previously known as MCT4 due to changes in isoform nomenclature) is at the basolateral membrane of human colon, and increases in abundance from the small intestine to the colon. Lin et al. (2019) demonstrated that MCT5 gene expression was significantly upregulated in colorectal adenocarcinoma, which suggests potential importance of MCT5 in gastrointestinal cancer. Additionally, the National Human Genome Research Institute-
European Bioinformatics Institute Catalog (Buniello et al., 2019) reports a SNP (rs17025736) that results in an intron variant of the human MCT5 gene that is associated with adolescent idiopathic scoliosis (Liu et al., 2018). However, further validation is required prior to confirming the impact of this variant on MCT5 function and its relation to this disease. In a knockdown study performed in HeLa cells, the strongest enhancement of West Nile virus infection was demonstrated when MCT5 was silenced, of all the genes silenced in the study (Krishnan et al., 2008; Fisel et al., 2018). Additional experimental data suggested that MCT5 may play a functional role as a viral replication resistance factor, which may provide a protective effect against the disease. Overall, the evidence regarding the potential importance of MCT5 in human health and disease remains limited to gene-related studies, and further investigation is necessary prior to confirming these associations in vivo.

\section{Monocarboxylate Transporter 6 (SLC16A5)}

Similar to MCT5, the studies evaluating MCT6 and its relation to human health and disease are limited. Regarding its substrate selectivity, MCT6 has been shown to transport a small set of xenobiotics: bumetanide, nateglinide, probenecid, and prostaglandin $\mathrm{F}_{2 \alpha}$; a series of aglycone flavonoids have been identified as inhibitors (Murakami et al., 2005; Kohyama et al., 2013; Jones et al., 2017). Confirming previous reports of MCT6 expression in the intestine (Gill et al., 2005), Kohyama et al. (2013) was able to demonstrate expression of MCT6 in the human small intestine and evaluate the apparent affinity of MCT6 for nateglinide. These findings suggested that MCT6 may play a role in the intestinal absorption of nateglinide; however, other transporters may also be involved. Besides only these two publications, there were no studies specifically studying MCT6 and its potential clinical role. Due to its ability to transport organic anion xenobiotics, others have also suggested that MCT6 may play a role in bumetanide's brain penetration (Römermann et al., 2017); however, further experimental evidence of MCT6 expression in the brain, as well as overall contribution to bumetanide distribution, has not been confirmed.

Regarding its potential utility as a biomarker for human disease, a DNA methylation study performed by Sugito et al. (2013) demonstrated that hypomethylation of MCT6, along with hypermethylation of a ZFN206, results in significantly prolonged eventfree survival in neuroblastomas. Similarly in brain, more recent transcriptomic studies have suggested that MCT6 may play a role as a biomarker in Alzheimer's disease risk (Boada et al., 2014; Wei et al., 2019); however, due to the lack of evidence demonstrating the expression of MCT6 in brain tissue, these associations remain to be evaluated experimentally.

More recently, a clinically significant variant (rs4788863) was identified for human SLC16A5 (Drögemöller et al., 
2017). This retrospective study reported that rs 4788863 resulted in a significant decrease in cisplatin-induced ototoxicity severity in testicular cancer patients. In addition, cisplatin dose-dependently induced SLC16A5 expression in HeLa cells; this may be indirectly related to the ototoxicity. Although this study was limited, it represented the first clinical evidence of MCT6 in relation to the pharmacological/toxicological effects of a drug. Although the mechanism underlying SLC16A5related ototoxicity of cisplatin is largely unknown, there is evidence to suggest that MCT6 may play a role in prevention of chemotherapy-induced hearing loss.

\section{E. Monocarboxylate Transporter 7 (SLC16A6)}

Although MCT7 has been studied with respect to the transport of ketone bodies, such as $\beta$-hydroxybutyrate, MCT7 has also been suggested to play a role in liver disease primarily from evidence gathered in preclinical models. In a zebrafish model of hepatic steatosis that results in a loss-of-function mutation for slc16a6a, the gene encoding for the orthologous equivalent of human MCT7, the introduction of the human $M C T 7$ gene results in a phenotypic rescue from this metabolic disorder (Hugo et al., 2012). This suggests an important role of MCT7 in maintaining intracellular ketone body homeostasis, which protects the cell from excess synthesis of triglycerides. Subsequently, Karanth and Schlegel (2019) demonstrated that homozygous slc16a6a mutants resulted in increased growth, and variants present in human MCT7 gene are strongly associated with human height. Although these variants still need to be validated experimentally, these in vitro experiments and associations provide initial evidence as to the potential functional role of MCT7 in humans. Not surprising due to its ability to transport ketone bodies, other in vivo evidence suggests that MCT7 is regulated by fasting and caloric restriction (Kim et al., 2016), which could impact its ability to maintain monocarboxylate homeostasis.

\section{F. Monocarboxylate Transporter 8 (SLC16A2)}

Besides MCTs 1-4, MCT8 is the most studied MCT isoform, due to its ability to influence thyroid hormone transport. A rare X-linked neurologic disorder, known as Allan-Herndon-Dudley syndrome (AHDS), is the consequence of various mutations in the MCT8 gene. These mutations lead to increased serum thyroid hormone: triiodothyronine $\left(\mathrm{T}_{3}\right)$, due to the decrease in its cellular uptake (Friesema et al., 2003; Dumitrescu et al., 2004, 2006; Schwartz et al., 2005; Trajkovic et al., 2007; Wirth et al., 2009). Due to these pronounced changes, those suffering from this disorder experience symptoms of intellectual disability and impaired muscular activity due to both lack of intracellular $\mathrm{T}_{3}$ and high plasma $\mathrm{T}_{3}$ (Schwartz et al., 2005; Novara et al., 2017). Currently, there is a Phase II clinical trial, which has not yet begun recruitment, aimed at evaluating treatment of AHDS-afflicted patients with Triac, a thyroid hormone analog that is not dependent on MCT8 for cellular uptake (NCT02396459).

\section{G. Monocarboxylate Transporter 10 (SLC16A10)}

MCT10, otherwise known as T-type amino acid transporter 1, is an aromatic amino acid transporter. Due to its relatively high amino acid identity to MCT8 (58\%), it is not surprising that MCT10 also shares some overlapping substrate selectivity with MCT8 for thyroid hormones (Johannes et al., 2016). A SNP in the MCT10 gene was associated with lower free plasma $T_{3}$ concentrations (van der Deure et al., 2007), which supports the role of MCT10 in the homeostasis of thyroid hormone levels. Besides contributing to the regulation of thyroid hormone concentrations, there is some preclinical evidence for the importance of MCT10 in maintaining circulating and liver aromatic amino acid concentrations in vivo (Mariotta et al., 2012). Although the contribution of MCT10 to aromatic amino acid homeostasis in humans has yet to be evaluated, this study provided preliminary evidence that it may play an important role. More recently, Lake et al. (2015) provided some of the first evidence for the functional role of MCT10 in aromatic amino acid transport and its potential relation to nonalcoholic steatohepatitis (NASH) due to the significant downregulation of gene expression. The authors concluded that this downregulation may be the potential cause for the increase in aromatic amino acid concentrations (specifically tyrosine and phenylalanine) in NASH liver samples. Whereas the specific mechanism of MCT10 in NASH and clinical utility of this finding have yet to be elucidated, it is apparent that this transporter is associated with NASH disease progression to some extent.

\section{H. Monocarboxylate Transporter 11 (SLC16A11)}

Recently, mutations in the gene encoding for MCT11 have been implicated in the risk of type II diabetes (T2D). A genome-wide association study conducted by the Slim Initiative in Genomic Medicine for the Americas T2D Consortium in a Mexican and other Latin American populations revealed a haplotype with four missense SNPs resulting in decreased functional activity of MCT11 (Williams et al., 2014; Rusu et al., 2017; Kimura et al., 2018). Another SNP (rs13342232) coding sequence mutation resulting in a synonymous variant (Leu > Leu) was found to be significantly associated with the occurrence of T2D in adults and children (Miranda-Lora et al., 2017). This variant also provided the first evidence of the role of MCT11 in determining the risk of early-onset T2D. The trafficking of MCT11 to the plasma membrane was shown to be mediated by basigin (CD147), an ancillary protein that plays a role in other MCT isoform membrane localization (Rusu et al., 2017). A study published by Rusu et al. (2017) described the disruption of this membrane trafficking in T2D as a consequence of MCT11 variants. Subsequently, 
additional research by Zhao et al. (2019) using a Mct11 knockout mouse model suggested that the mutant murine Mct11 protein gained abnormal function, resulting in altered lipid metabolism that contributes to the development of T2D. Although the specific mechanisms by which MCT11 plays a role in T2D risk and progression have yet to be clarified, the evidence for a clinical impact of this transporter in T2D warrants further experimental investigation.

\section{Monocarboxylate Transporter 12 (SLC16A12)}

In 2008, a nonsense mutation in the gene encoding for MCT12 was identified in a Swiss family with autosomal dominant juvenile cataracts, microcornea, as well as renal glucosuria (Kloeckener-Gruissem et al., 2008). In addition, this study demonstrated positive gene expression of MCT12 in kidney tissue as well as multiple sites in the eye, including the retina, retinal pigmental epithelium, and lens in a human donor eye. The study was the first to conclude a potential importance in the pathogenesis of MCT12 in eye-related diseases. Following this study, a SNP was identified in the 5'UTR of MCT12, which provided evidence for its role in regulation of translational efficiency that could potentially be associated with age-related cataracts (Zuercher et al., 2010). Further investigation into the reported heterozygous nonsense mutation in the coding region of MCT12 of exon 6 yielded evidence that suggested that the variant most likely impacts correct protein folding and trafficking with basigin, which was supported using a humanized rat model (Castorino et al., 2011b). In the same laboratory, Abplanalp et al. (2013) provided in vitro and in vivo evidence for the role of MCT12 in creatine transporter, which supported a plausible mechanism by which MCT12 mutations lead to perturbations in the eye. After further research performed on MCT12 activity, substrate selectivity, and analysis of a separate mutation in the sodium/glucose cotransporter 2 gene (SGLT2; SLC5A2), it was determined that MCT12 most likely affects the renal handling of creatine transport and systemic concentrations of its precursor, guanidinoacetate (Dhayat et al., 2016). However, the mechanism by which the mutation in MCT12 alters guanidinoacetate remains unclear. Additionally, the phenotype of renal glucosuria, present in the Swiss family, was attributed primarily to the mutation in SGLT2. Later studies investigating exogenous supplementation of basigin and its ability to partially rescue the decreased activity of MCT12 mutations supported the importance of MCT12basigin interactions in the development of age-related cataracts (Stäubli et al., 2017).

\section{J. Monocarboxylate Transporter 13/14 (SLC16A13/16A14)}

There is sparse information on MCT13 and MCT14 in the literature regarding their substrate selectivity and functional role in human health and disease. Evidence demonstrates that T2D-associated variants span the adjacent MCT11 and MCT13 gene loci, and suggests that MCT13 may play a functional role in T2D risk; however, there is no experimental evidence to support this association (Rusu et al., 2017). Regarding MCT14, initial studies investigating the gene and protein expression of murine Mct14 revealed positive histologic staining of the protein in excitatory, inhibitory neurons, and epithelial cells (Roshanbin et al., 2016). Additionally, MCT14 gene expression increased 2.1-fold following treatment with ethanol for 48 hours versus no treatment in immortalized lymphoblastoid cells originally isolated from subjects enrolled in the Collaborative Study on the Genetics of Alcoholism (McClintick et al., 2019). The relevance of MCT14 and alcohol consumption remains uncertain, but this study provides some transcriptional evidence for this association. A summary of the potential role of MCTs in health and disease is present in Table 4.

\section{Findings from the Use of Genetically-Modified Mct Rodent Models}

To gain a better understanding of each MCT isoform in vivo, genetically modified rodent mouse models have been developed for experimental characterization.

\section{A. Monocarboxylate Transporter 1}

Because the Mct1 homozygous mouse model results in embryonic lethality, a haploinsufficient $\left(\mathrm{Mct1}^{+/-}\right)$mouse model was developed to understand MCT1 in diet-induced obesity and cellular energy homeostasis (Lengacher et al., 2013; Chatel et al., 2017). Because of the ubiquitous expression and importance of Mct1 in transporting protons, short chain fatty acids, and energy utilization, it was understandable that this mouse model suggested that Mct1 played a role in resistance to weight gain from a high-fat diet, as well as $\mathrm{pH}$ homeostasis in skeletal muscle. Using the same model, it was also shown that downregulation of Mct1 resulted in impairment of longterm memory development (Tadi et al., 2015). This is supported by the dominant role of MCT1 in the brain and its responsibility in the neuron-astrocyte lactate shuttle (Vijay and Morris, 2014; Pérez-Escuredo et al., 2016).

\section{B. Monocarboxylate Transporter 2}

Currently, there has been no known Mct2 genetic knockout mouse model developed. However, humanized MCT2 transgenic mice were developed to evaluate its contribution to the effects of sleep apnea (Wang et al., 2011). Interestingly, decreases in human MCT2 expression and function in these mice were related, in part, to increased central nervous system vulnerability to the effects of sleep apnea.

\section{Monocarboxylate Transporter 3}

Due to its expression and localization in the retinal pigment epithelium (Yoon et al., 1997; Philp et al., 
TABLE 4

MCT variants and MCT up/downregulation in disease

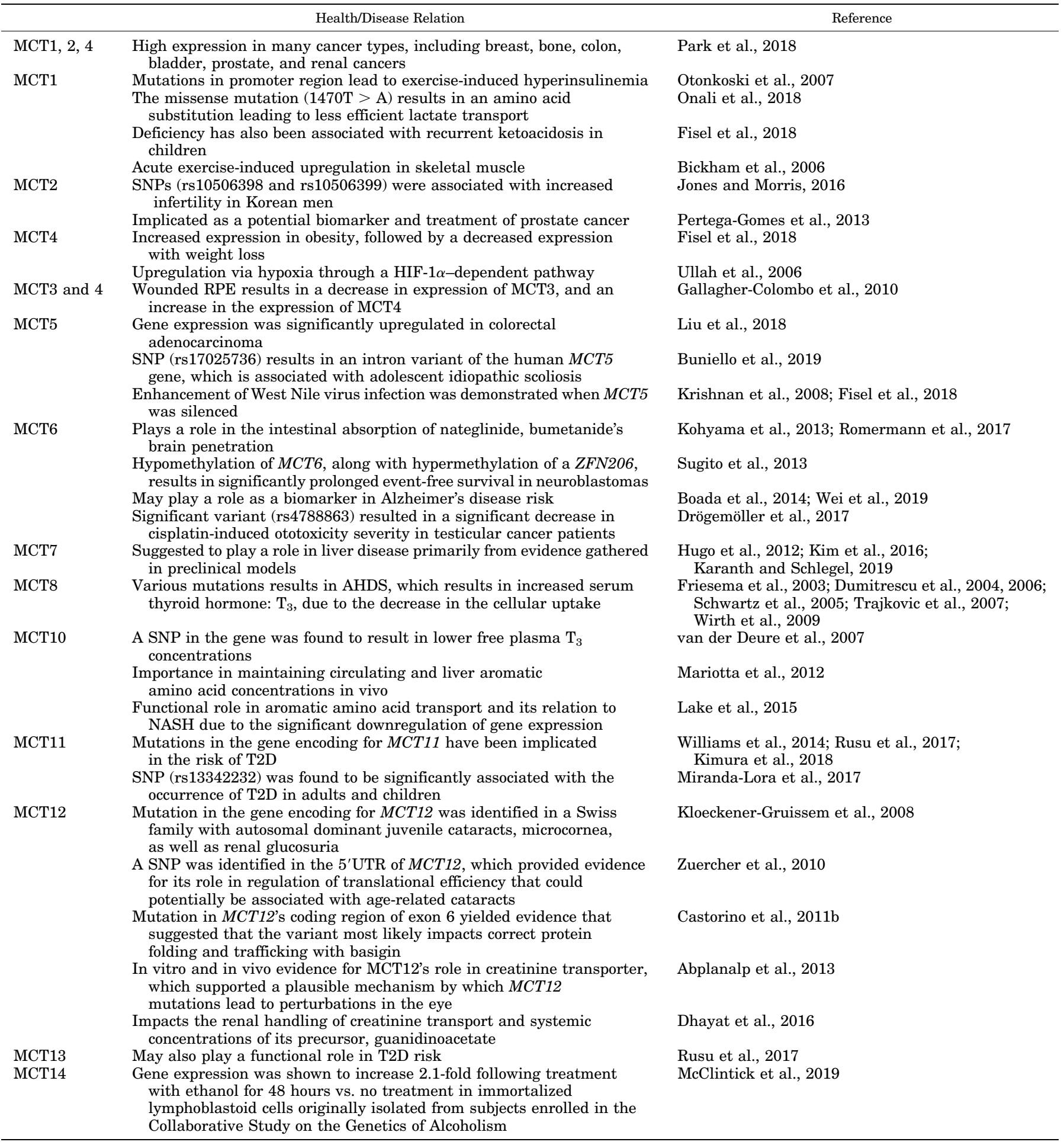

2001; Gallagher-Colombo et al., 2010), researchers suggested that MCT3 may be involved in similar functions of MCTs 1-4, such as $\mathrm{pH}$ and monocarboxylate homeostasis in the eye. Mct3 knockout mice were generated to investigate this hypothesis, and it was found that $\mathrm{Mct} 3^{-/-}$mice demonstrated significant differences in lactate concentration and $\mathrm{pH}$ in the retina (Daniele et al., 2008). Because of these findings, the authors concluded that inhibition of Mct3 can have an overall impact on $\mathrm{pH}$-sensitive regulation of vision.

\section{Monocarboxylate Transporter 4}

MCT4 has been shown to be upregulated in a wide variety of cancers (Pinheiro et al., 2010; Gotanda et al., 
2013; Yan et al., 2014; Baenke et al., 2015), and, because of this, researchers have become increasingly interested in understanding its role in these diseases. In particular, high MCT4 expression in head and neck squamous cell carcinoma has been associated with poor prognosis. Because of this finding, researchers investigated whether MCT4 played a major role in oral cancer. Mct4 ${ }^{-1-}$ mice demonstrated that Mct4 was a potential driver of oral squamous cell cancer disease progression (Bisetto et al., 2018). In addition, unlike $\mathrm{Mct}^{-1-}$ mice resulting in lethality, $\mathrm{Mct}^{-1-}$ mice were almost indistinguishable from wild-type control mice.

\section{E. Monocarboxylate Transporter 8}

MCT8 is an important thyroid hormone transporter in the brain, as well as the major contributor to the X-linked mutation causing AHDS (Schwartz et al., 2005). To study MCT8 and its importance in thyroid hormone homeostasis, numerous studies have been performed using a $\mathrm{Mct}^{-/-}$mouse model (Dumitrescu et al., 2006; Di Cosmo et al., 2010; Mayerl et al., 2014; Stohn et al., 2016). These studies indicated that Mct8 significantly contributed to the intracellular thyroid hormone concentrations. In addition, the role of Mct8 in thyroid hormone secretion from the thyroid gland was also demonstrated in this mouse model, suggesting its potential impact on thyroid hormone regulation in MCT8-deficient patients. As well as the thyroid gland and the brain, Mct8 was found to be a significant contributor to bone maintenance, suggesting that this transporter has multitissue roles in thyroid hormone homeostasis. Of all the MCT isoforms currently being studied outside of MCTs 1-4, it is apparent that MCT8 is a significant determinant of thyroid hormone homeostasis.

\section{F. Monocarboxylate Transporter 10}

Similarly, due to its ability to transport thyroid hormone and similarity in phylogeny to MCT8, Mct10 ${ }^{-/-}$ mice were generated to understand its contribution in the thyroid hormone homeostasis pathway (Müller et al., 2014). Interestingly, the role of Mct8 and Mct10 was shown to be shared when perturbations were seen in the serum thyroid hormone profile of $\mathrm{Mct}^{-/-}$mice. In addition, when the double-knockout mice were generated (Mct8 $^{-/} / \mathrm{Mct}^{-/-}$), these mice exhibited loss of cochlear hair cells, resulting in deafness, suggesting an importance of thyroid hormone transport in ear development (Sharlin et al., 2018).

\section{G. Monocarboxylate Transporter 12}

Considering MCT12 mutations have been associated with cataracts (Abplanalp et al., 2013; Stäubli et al., 2017), researchers developed a transgenic Slc16a12 rat model to verify the contribution of MCT12 and a mutant allele to cataract formation (Castorino et al., 2011b). Further research, however, is needed to confirm the mechanism by which MCT12 contributes to this pathway.

\section{H. Other Monocarboxylate Transporter Isoforms}

No other genetically modified animal models have been developed for the study of other Mct isoforms.

\section{Conclusions and Future Studies}

The SLC16 family of transporters represents a significant group of 14 membrane proteins important for the disposition of both xenobiotics and endogenous compounds. Given their extensive tissue distribution and broad range of substrates, MCTs have the potential to influence the pharmacokinetics of many endogenous compounds and pharmaceutical compounds. Of particular note, protein expression of MCTs is present in critical tissues for elimination and absorption, including the liver, kidney, intestines, and the blood brain barrier. The importance of members of the SLC16 family, including MCT1-4 and MCT8, is now well recognized. Of note, MCTs 1 and 4 are overexpressed in cancers, and inhibition of transport represents a current area of investigation as a chemotherapeutic strategy in cancers. A mutation in the MCT8 (SLC16A2) gene (located on the $\mathrm{X}$ chromosome) causes an X-linked psychomotor intellectual disability, due to limited thyroid hormone uptake at the blood brain barrier, leading to lack of normal brain development.

Research in elucidating the role of other MCT isoforms will add significantly to the current knowledge of this 14-member transporter family. Several MCT isoforms remain classified as orphan transporters, meaning that they have no known endogenous substrates or physiologic role. These transporters were outlined in a publication by Halestrap (2013b) in which MCTs 5-7, 9, and 11-14 were defined as being orphan transporters. Since then, the functions of some of these orphan transporters have been partially characterized. In 2017, mutations in SLC16A12 (MCT12) were identified in patients with age-related cataracts (Stäubli et al., 2017). These mutations, resulting in abnormal creatine transport, suggested that MCT12 plays a major role in the prevention of cataract formation. Additionally, a haplotype consisting of five variants for human SLC16A11 (MCT11) resulted in decreased MCT11 gene expression and cell surface localization (Rusu et al., 2017). This haplotype resulted in changes in fatty acid and lipid metabolism and was significantly associated with the increased T2D risk in a Mexican population. The authors concluded that this association with T2D risk suggested that MCT11 induction could be therapeutically beneficial. In the same year, a synonymous mutation in the coding region of SLC16A5 (MCT6) (rs4788863, p.Leu41Leu), which was predicted to decrease the rate of codon usage (potentially decreasing protein translation), resulted in a protective effect from cisplatin-induced ototoxicity in patients with testicular cancer (Drögemöller et al., 2017). However, the mechanism behind this protective effect has yet to be 
evaluated. Although there has been an increase in research on MCTs within the last few years, further research elucidating the functions of the $14 \mathrm{MCTs}$ is needed to understand the role of these transporters in both drug disposition and endogenous compound homeostasis, as well as their roles as potential targets in disease.

\section{Authorship Contributions}

Wrote or contributed to the writing of the manuscript: Jones, Felmlee, Rodriguez-Cruz, Follman, Morris.

\section{References}

Abplanalp J, Laczko E, Philp NJ, Neidhardt J, Zuercher J, Braun P, Schorderet DF, Munier FL, Verrey F, Berger W, et al. (2013) The cataract and glucosuria associated monocarboxylate transporter MCT12 is a new creatine transporter. Hum Mol Genet 22:3218-3226.

Ames S, Pastorekova S, and Becker HM (2018) The proteoglycan-like domain of carbonic anhydrase IX mediates non-catalytic facilitation of lactate transport in cancer cells. Oncotarget 9:27940-27957.

Asada K, Miyamoto K, Fukutomi T, Tsuda H, Yagi Y, Wakazono K, Oishi S, Fukui H, Sugimura T, and Ushijima T (2003) Reduced expression of GNA11 and silencing of MCT1 in human breast cancers. Oncology 64:380-388.

Aspatwar A, Tolvanen MEE, Schneider HP, Becker HM, Narkilahti S, Parkkila S, and Deitmer JW (2019) Catalytically inactive carbonic anhydrase-related proteins enhance transport of lactate by MCT1. FEBS Open Bio 9:1204-1211.

Baenke F, Dubuis S, Brault C, Weigelt B, Dankworth B, Griffiths B, Jiang M, Mackay A, Saunders B, Spencer-Dene B, et al. (2015) Functional screening identifies MCT4 as a key regulator of breast cancer cell metabolism and survival. J Pathol 237: $152-165$.

Banerjee A, Shukla S, Pandey AD, Goswami S, Bandyopadhyay B, Ramachandran V, Das S, Malhotra A, Agarwal A, Adhikari S, et al. (2017) RNA-Seq analysis of peripheral blood mononuclear cells reveals unique transcriptional signatures associated with disease progression in dengue patients. Transl Res 186:62-78.e9.

Baud O, Fayol L, Gressens P, Pellerin L, Magistretti P, Evrard P, and Verney C (2003) Perinatal and early postnatal changes in the expression of monocarboxylate transporters MCT1 and MCT2 in the rat forebrain. J Comp Neurol 465:445-454.

Becker HM and Deitmer JW (2008) Nonenzymatic proton handling by carbonic anhydrase II during $\mathrm{H}+$-lactate cotransport via monocarboxylate transporter 1. $J$ Biol Chem 283:21655-21667.

Becker HM, Hirnet D, Fecher-Trost C, Sültemeyer D, and Deitmer JW (2005) Transport activity of MCT1 expressed in Xenopus oocytes is increased by interaction with carbonic anhydrase. J Biol Chem 280:39882-39889.

Becker HM, Klier M, and Deitmer JW (2010a) Nonenzymatic augmentation of lactate transport via monocarboxylate transporter isoform 4 by carbonic anhydrase II. $J$ Membr Biol 234:125-135.

Becker HM, Mohebbi N, Perna A, Ganapathy V, Capasso G, and Wagner CA (2010b) Localization of members of MCT monocarboxylate transporter family Slc16 in the kidney and regulation during metabolic acidosis. Am J Physiol Renal Physiol $\mathbf{2 9 9}$ F141-F154.

Bickham DC, Bentley DJ, Le Rossignol PF, and Cameron-Smith D (2006) The effects of short-term sprint training on MCT expression in moderately endurance-trained runners. Eur J Appl Physiol 96:636-643.

Bisetto S, Whitaker-Menezes D, Wilski NA, Tuluc M, Curry J, Zhan T, Snyder CM, Martinez-Outschoorn UE, and Philp NJ (2018) Monocarboxylate transporter 4 (MCT4) knockout mice have attenuated 4NQO induced carcinogenesis; a role for MCT4 in driving oral squamous cell cancer. Front Oncol 8:324.

Boada M, Antúnez C, Ramírez-Lorca R, DeStefano AL, González-Pérez A, Gayán J, López-Arrieta J, Ikram MA, Hernández I, Marín J, et al.; Alzheimer's Disease Neuroimaging Initiative (2014) ATP5H/KCTD2 locus is associated with Alzheimer's disease risk. Mol Psychiatry 19:682-687.

Bonen A, Heynen M, and Hatta H (2006) Distribution of monocarboxylate transporters MCT1-MCT8 in rat tissues and human skeletal muscle. Appl Physiol Nutr Metab 31:31-39.

Borthakur A, Saksena S, Gill RK, Alrefai WA, Ramaswamy K, and Dudeja PK (2008) Regulation of monocarboxylate transporter 1 (MCT1) promoter by butyrate in human intestinal epithelial cells: involvement of NF-kappaB pathway. J Cell Biochem 103:1452-1463.

Boussouar F, Mauduit C, Tabone E, Pellerin L, Magistretti PJ, and Benahmed M (2003) Developmental and hormonal regulation of the monocarboxylate transporter 2 (MCT2) expression in the mouse germ cells. Biol Reprod 69:1069-1078.

Brix B, Mesters JR, Pellerin L, and Jöhren O (2012) Endothelial cell-derived nitric oxide enhances aerobic glycolysis in astrocytes via HIF-1 $\alpha$-mediated target gene activation. J Neurosci 32:9727-9735.

Bröer S, Bröer A, Schneider HP, Stegen C, Halestrap AP, and Deitmer JW (1999) Characterization of the high-affinity monocarboxylate transporter MCT2 in Xenopus laevis oocytes. Biochem J 341:529-535.

Bröer S, Schneider HP, Bröer A, Rahman B, Hamprecht B, and Deitmer JW (1998) Characterization of the monocarboxylate transporter 1 expressed in Xenopus laevis oocytes by changes in cytosolic $\mathrm{pH}$. Biochem $J$ 333:167-174.

Buniello A, MacArthur JAL, Cerezo M, Harris LW, Hayhurst J, Malangone C, McMahon A, Morales J, Mountjoy E, Sollis E, et al. (2019) The NHGRI-EBI GWAS Catalog of published genome-wide association studies, targeted arrays and summary statistics 2019. Nucleic Acids Res 47:D1005-D1012.
Cao J, Ng M, and Felmlee MA (2017) Sex hormones regulate rat hepatic monocarboxylate transporter expression and membrane trafficking. J Pharm Pharm Sci 20:435-444.

Castorino JJ, Deborde S, Deora A, Schreiner R, Gallagher-Colombo SM, Rodriguez-Boulan E, and Philp NJ (2011a) Basolateral sorting signals regulating tissue-specific polarity of heteromeric monocarboxylate transporters in epithelia. Traffic 12:483-498.

Castorino JJ, Gallagher-Colombo SM, Levin AV, Fitzgerald PG, Polishook J, Kloeckener-Gruissem B, Ostertag E, and Philp NJ (2011b) Juvenile cataractassociated mutation of solute carrier SLC16A12 impairs trafficking of the protein to the plasma membrane. Invest Ophthalmol Vis Sci 52:6774-6784.

Chatel B, Bendahan D, Hourdé C, Pellerin L, Lengacher S, Magistretti P, Le Fur Y, Vilmen C, Bernard M, and Messonnier LA (2017) Role of MCT1 and CAII in skeletal muscle $\mathrm{pH}$ homeostasis, energetics, and function: in vivo insights from MCT1 haploinsufficient mice. FASEB J 31:2562-2575.

Chen C, Zhang C, Cheng L, Reilly JL, Bishop JR, Sweeney JA, Chen HY, Gershon ES, and Liu C (2014) Correlation between DNA methylation and gene expression in the brains of patients with bipolar disorder and schizophrenia. Bipolar Disord 16:790-799.

Cicek MS, Koestler DC, Fridley BL, Kalli KR, Armasu SM, Larson MC, Wang C, Winham SJ, Vierkant RA, Rider DN, et al. (2013) Epigenome-wide ovarian cancer analysis identifies a methylation profile differentiating clear-cell histology with epigenetic silencing of the HERG K+ channel. Hum Mol Genet 22:3038-3047.

Cuff MA, Lambert DW, and Shirazi-Beechey SP (2002) Substrate-induced regulation of the human colonic monocarboxylate transporter, MCT1. J Physiol 539:361-371.

Cuff MA and Shirazi-Beechey SP (2002) The human monocarboxylate transporter, MCT1: genomic organization and promoter analysis. Biochem Biophys Res Commun 292:1048-1056.

Cundy KC, Branch R, Chernov-Rogan T, Dias T, Estrada T, Hold K, Koller K, Liu X, Mann A, Panuwat M, et al. (2004) XP13512 [(+/-)-1-([(alpha-isobutanoyloxyethoxy) carbonyl] aminomethyl)-1-cyclohexane acetic acid], a novel gabapentin prodrug: I. Design, synthesis, enzymatic conversion to gabapentin, and transport by intestinal solute transporters. J Pharmacol Exp Ther 311:315-323.

Cupeiro R, González-Lamuño D, Amigo T, Peinado AB, Ruiz JR, Ortega FB, and Benito PJ (2012) Influence of the MCT1-T1470A polymorphism (rs1049434) on blood lactate accumulation during different circuit weight trainings in men and women. J Sci Med Sport 15:541-547.

Curtis NJ, Mooney L, Hopcroft L, Michopoulos F, Whalley N, Zhong H, Murray C, Logie A, Revill M, Byth KF, et al. (2017) Pre-clinical pharmacology of AZD3965, a selective inhibitor of MCT1: DLBCL, NHL and Burkitt's lymphoma anti-tumor activity. Oncotarget 8:69219-69236.

Daniele LL, Sauer B, Gallagher SM, Pugh EN Jr., and Philp NJ (2008) Altered visual function in monocarboxylate transporter 3 (Slc16a8) knockout mice. Am J Physiol Cell Physiol 295:C451-C457.

Deora AA, Philp N, Hu J, Bok D, and Rodriguez-Boulan E (2005) Mechanisms regulating tissue-specific polarity of monocarboxylate transporters and their chaperone CD147 in kidney and retinal epithelia. Proc Natl Acad Sci USA 102:16245-16250.

Dhayat N, Simonin A, Anderegg M, Pathare G, Lüscher BP, Deisl C, Albano G, Mordasini D, Hediger MA, Surbek DV, et al. (2016) Mutation in the monocarboxylate transporter 12 gene affects guanidinoacetate excretion but does not cause glucosuria. J Am Soc Nephrol 27:1426-1436.

Di Cosmo C, Liao XH, Dumitrescu AM, Philp NJ, Weiss RE, and Refetoff S (2010) Mice deficient in MCT8 reveal a mechanism regulating thyroid hormone secretion. $J$ Clin Invest 120:3377-3388.

Diehl K, Dinges LA, Helm O, Ammar N, Plundrich D, Arlt A, Röcken C, Sebens S, and Schäfer H (2018) Nuclear factor E2-related factor-2 has a differential impact on MCT1 and MCT4 lactate carrier expression in colonic epithelial cells: a condition favoring metabolic symbiosis between colorectal cancer and stromal cells. Oncogene 37:39-51.

Dimmer KS, Friedrich B, Lang F, Deitmer JW, and Bröer S (2000) The low-affinity monocarboxylate transporter MCT4 is adapted to the export of lactate in highly glycolytic cells. Biochem $J$ 350:219-227.

Doherty JR, Yang C, Scott KE, Cameron MD, Fallahi M, Li W, Hall MA, Amelio AL Mishra JK, Li F, et al. (2014) Blocking lactate export by inhibiting the Myc target MCT1 disables glycolysis and glutathione synthesis. Cancer Res 74:908-920.

Draoui N and Feron O (2011) Lactate shuttles at a glance: from physiological paradigms to anti-cancer treatments. Dis Model Mech 4:727-732.

Drögemöller BI, Monzon JG, Bhavsar AP, Borrie AE, Brooks B, Wright GEB, Liu G, Renouf DJ, Kollmannsberger CK, Bedard PL, et al. (2017) Association between SLC16A5 genetic variation and cisplatin-induced ototoxic effects in adult patients with testicular cancer. JAMA Oncol 3:1558-1562.

Dumitrescu AM, Liao XH, Best TB, Brockmann K, and Refetoff S (2004) A novel syndrome combining thyroid and neurological abnormalities is associated with mutations in a monocarboxylate transporter gene. Am J Hum Genet 74:168-175.

Dumitrescu AM, Liao XH, Weiss RE, Millen K, and Refetoff S (2006) Tissue-specific thyroid hormone deprivation and excess in monocarboxylate transporter (mct) 8 deficient mice. Endocrinology 147:4036-4043.

England EM, Shi H, Matarneh SK, Oliver EM, Helm ET, Scheffler TL, Puolanne E, and Gerrard DE (2017) Chronic activation of AMP-activated protein kinase increases monocarboxylate transporter 2 and 4 expression in skeletal muscle. J Anim Sci 95:3552-3562.

Enoki T, Yoshida Y, Lally J, Hatta H, and Bonen A (2006) Testosterone increases lactate transport, monocarboxylate transporter (MCT) 1 and MCT4 in rat skeletal muscle. J Physiol 577:433-443.

Erdmann P, Bruckmueller H, Martin P, Busch D, Haenisch S, Müller J, WiechowskaKozlowska A, Partecke LI, Heidecke CD, Cascorbi I, et al. (2019) Dysregulation of mucosal membrane transporters and drug-metabolizing enzymes in ulcerative colitis. J Pharm Sci 108:1035-1046.

Fisel P, Kruck S, Winter S, Bedke J, Hennenlotter J, Nies AT, Scharpf M, Fend F, Stenzl A, Schwab M, et al. (2013) DNA methylation of the SLC16A3 promoter regulates expression of the human lactate transporter MCT4 in renal cancer with consequences for clinical outcome. Clin Cancer Res 19:5170-5181. 
Fisel P, Schaeffeler E, and Schwab M (2018) Clinical and functional relevance of the monocarboxylate transporter family in disease pathophysiology and drug therapy. Clin Transl Sci 11:352-364.

Fisel P, Stühler V, Bedke J, Winter S, Rausch S, Hennenlotter J, Nies AT, Stenzl A, Scharpf M, Fend F, et al. (2015) MCT4 surpasses the prognostic relevance of the ancillary protein CD147 in clear cell renal cell carcinoma. Oncotarget 6:30615-30627.

Forero-Quintero LS, Ames S, Schneider HP, Thyssen A, Boone CD, Andring JT, McKenna R, Casey JR, Deitmer JW, and Becker HM (2019) Membrane-anchored carbonic anhydrase IV interacts with monocarboxylate transporters via their chaperones CD147 and GP70. J Biol Chem 294:593-607.

Friesema EC, Ganguly S, Abdalla A, Manning Fox JE, Halestrap AP, and Visser TJ (2003) Identification of monocarboxylate transporter 8 as a specific thyroid hormone transporter. J Biol Chem 278:40128-40135.

Friesema EC, Kuiper GG, Jansen J, Visser TJ, and Kester MH (2006) Thyroid hormone transport by the human monocarboxylate transporter 8 and its rate-limiting role in intracellular metabolism. Mol Endocrinol 20:2761-2772.

Friesema EC, Visser TJ, Borgers AJ, Kalsbeek A, Swaab DF, Fliers E, and Alkemade A (2012) Thyroid hormone transporters and deiodinases in the developing human hypothalamus. Eur J Endocrinol 167:379-386.

Furugen A, Kobayashi M, Narumi K, Watanabe M, Otake S, Itagaki S, and Iseki K (2011) AMP-activated protein kinase regulates the expression of monocarboxylate transporter 4 in skeletal muscle. Life Sci 88:163-168.

Gallagher-Colombo S, Maminishkis A, Tate S, Grunwald GB, and Philp NJ (2010) Modulation of MCT3 expression during wound healing of the retinal pigment epithelium. Invest Ophthalmol Vis Sci 51:5343-5350.

Ganapathy V, Thangaraju M, Gopal E, Martin PM, Itagaki S, Miyauchi S, and Prasad PD (2008) Sodium-coupled monocarboxylate transporters in normal tissues and in cancer. AAPS $J$ 10:193-199.

Garcia CK, Li X, Luna J, and Francke U (1994) cDNA cloning of the human monocarboxylate transporter 1 and chromosomal localization of the SLC16A1 locus to 1p13.2-p12. Genomics 23:500-503.

Gill RK, Saksena S, Alrefai WA, Sarwar Z, Goldstein JL, Carroll RE, Ramaswamy K, and Dudeja PK (2005) Expression and membrane localization of MCT isoforms along the length of the human intestine. Am J Physiol Cell Physiol 289:C846-C852.

Gotanda Y, Akagi Y, Kawahara A, Kinugasa T, Yoshida T, Ryu Y, Shiratsuchi I, Kage M, and Shirouzu K (2013) Expression of monocarboxylate transporter (MCT)-4 in colorectal cancer and its role: MCT4 contributes to the growth of colorectal cancer with vascular endothelial growth factor. Anticancer Res 33:2941-2947.

Guan X, Rodriguez-Cruz V, and Morris ME (2019) Cellular uptake of MCT1 inhibitors AR-C155858 and AZD3965 and their effects on MCT-mediated transport of L-lactate in murine 4T1 breast tumor cancer cells. AAPS J 21:13

Hadjiagapiou C, Borthakur A, Dahdal RY, Gill RK, Malakooti J, Ramaswamy K, and Dudeja PK (2005) Role of USF1 and USF2 as potential repressor proteins for human intestinal monocarboxylate transporter 1 promoter. Am J Physiol Gastrointest Liver Physiol 288:G1118-G1126.

Halestrap AP (1976) Transport of pyruvate and lactate into human erythrocytes: evidence for the involvement of the chloride carrier and a chloride-independent carrier. Biochem J 156:193-207.

Halestrap AP (2012) The monocarboxylate transporter family--Structure and functional characterization. IUBMB Life 64:1-9.

Halestrap AP (2013a) Monocarboxylic acid transport. Compr Physiol 3:1611-1643.

Halestrap AP (2013b) The SLC16 gene family - structure, role and regulation in health and disease. Mol Aspects Med 34:337-349.

Halestrap AP and Denton RM (1974) Specific inhibition of pyruvate transport in rat liver mitochondria and human erythrocytes by alpha-cyano-4-hydroxycinnamate. Biochem J 138:313-316.

Halestrap AP and Meredith D (2004) The SLC16 gene family - from monocarboxylate transporters (MCTs) to aromatic amino acid transporters and beyond. Pflugers Arch 447:619-628

Halestrap AP and Price NT (1999) The proton-linked monocarboxylate transporter (MCT) family: structure, function and regulation. Biochem $J$ 343:281-299.

Halestrap AP and Wilson MC (2012) The monocarboxylate transporter family--role and regulation. IUBMB Life 64:109-119.

Hatta H, Tonouchi M, Miskovic D, Wang Y, Heikkila JJ, and Bonen A (2001) Tissuespecific and isoform-specific changes in MCT1 and MCT4 in heart and soleus muscle during a 1-yr period. Am J Physiol Endocrinol Metab 281:E749-E756.

Hirai T, Fukui Y, and Motojima K (2007) PPARalpha agonists positively and negatively regulate the expression of several nutrient/drug transporters in mouse small intestine. Biol Pharm Bull 30:2185-2190.

Hori K, Katayama N, Kachi S, Kondo M, Kadomatsu K, Usukura J, Muramatsu T, Mori S, and Miyake Y (2000) Retinal dysfunction in basigin deficiency. Invest Ophthalmol Vis Sci 41:3128-3133.

Hsiao KY, Wu MH, Chang N, Yang SH, Wu CW, Sun HS, and Tsai SJ (2015) Coordination of AUF1 and miR-148a destabilizes DNA methyltransferase 1 mRNA under hypoxia in endometriosis. Mol Hum Reprod 21:894-904.

Hudson J, Duncavage E, Tamburrino A, Salerno P, Xi L, Raffeld M, Moley J, and Chernock RD (2013) Overexpression of miR-10a and miR-375 and downregulation of YAP1 in medullary thyroid carcinoma. Exp Mol Pathol 95:62-67.

Hugo SE, Cruz-Garcia L, Karanth S, Anderson RM, Stainier DY, and Schlegel A (2012) A monocarboxylate transporter required for hepatocyte secretion of ketone bodies during fasting. Genes Dev 26:282-293.

Ito K, Uchida Y, Ohtsuki S, Aizawa S, Kawakami H, Katsukura Y, Kamiie J, and Terasaki T (2011) Quantitative membrane protein expression at the bloodbrain barrier of adult and younger cynomolgus monkeys. J Pharm Sci 100 3939-3950.

Jackson VN, Price NT, and Halestrap AP (1995) cDNA cloning of MCT1, a monocarboxylate transporter from rat skeletal muscle. Biochim Biophys Acta 1238: 193-196.

Jamali S, Klier M, Ames S, Barros LF, McKenna R, Deitmer JW, and Becker HM (2015) Hypoxia-induced carbonic anhydrase IX facilitates lactate flux in human breast cancer cells by non-catalytic function. Sci Rep 5:13605.
Johannes J, Braun D, Kinne A, Rathmann D, Köhrle J, and Schweizer U (2016) Few amino acid exchanges expand the substrate spectrum of monocarboxylate transporter 10. Mol Endocrinol 30:796-808.

Jones RS and Morris ME (2016) Monocarboxylate transporters: therapeutic targets and prognostic factors in disease. Clin Pharmacol Ther 100:454-463.

Jones RS, Parker MD, and Morris ME (2017) Quercetin, morin, luteolin, and phloretin are dietary flavonoid inhibitors of monocarboxylate transporter 6. Mol Pharm 14:2930-2936.

Juel C and Halestrap AP (1999) Lactate transport in skeletal muscle - role and regulation of the monocarboxylate transporter. J Physiol 517:633-642.

Karanth S and Schlegel A (2019) The monocarboxylate transporter SLC16A6 regulates adult length in zebrafish and is associated with height in humans. Front Physiol 9:1936.

Kim DK, Kanai Y, Chairoungdua A, Matsuo H, Cha SH, and Endou H (2001) Expression cloning of a $\mathrm{Na}+$-independent aromatic amino acid transporter with structural similarity to $\mathrm{H}+/$ monocarboxylate transporters. $J$ Biol Chem $\mathbf{2 7 6}$ 17221-17228.

Kim KE, Jung Y, Min S, Nam M, Heo RW, Jeon BT, Song DH, Yi CO, Jeong EA, Kim $\mathrm{H}$, et al. (2016) Caloric restriction of db/db mice reverts hepatic steatosis and body weight with divergent hepatic metabolism. Sci Rep 6:30111.

Kimura Y, Kobayashi M, Asari M, Higuchi I, Narumi K, Furugen A, and Iseki K (2018) Genetic variations in the monocarboxylate transporter genes (SLC16A1, SLC16A3, and SLC16A11) in the Japanese population. Drug Metab Pharmacokinet 33:215-218.

Kirk P, Wilson MC, Heddle C, Brown MH, Barclay AN, and Halestrap AP (2000) CD147 is tightly associated with lactate transporters MCT1 and MCT4 and facilitates their cell surface expression. EMBO J 19:3896-3904

Kitaoka Y, Hoshino D, Mukai K, Hiraga A, Takemasa T, and Hatta H (2011a) Effect of growth on monocarboxylate transporters and indicators of energy metabolism in the gluteus medius muscle of thoroughbreds. Am J Vet Res 72:1107-1111.

Kitaoka Y, Machida M, Takemasa T, and Hatta H (2011b) Expression of monocarboxylate transporter (MCT) 1 and MCT4 in overloaded mice plantaris muscle. $J$ Physiol Sci 61:467-472.

Kitaoka Y, Takahashi Y, Machida M, Takeda K, Takemasa T, and Hatta H (2014) Effect of AMPK activation on monocarboxylate transporter (MCT)1 and MCT4 in denervated muscle. J Physiol Sci 64:59-64.

Klier M, Andes FT, Deitmer JW, and Becker HM (2014) Intracellular and extracellular carbonic anhydrases cooperate non-enzymatically to enhance activity of monocarboxylate transporters. J Biol Chem 289:2765-2775.

Klier M, Schüler C, Halestrap AP, Sly WS, Deitmer JW, and Becker HM (2011) Transport activity of the high-affinity monocarboxylate transporter MCT2 is enhanced by extracellular carbonic anhydrase IV but not by intracellular carbonic anhydrase II. J Biol Chem 286:27781-27791.

Kloeckener-Gruissem B, Vandekerckhove K, Nürnberg G, Neidhardt J, Zeitz C, Nürnberg P, Schipper I, and Berger W (2008) Mutation of solute carrier SLC16A12 associates with a syndrome combining juvenile cataract with microcornea and renal glucosuria. Am J Hum Genet 82:772-779.

Knyazev EN, Mal'tseva DV, Zacharyants AA, Zakharova GS, Zhidkova OV, and Poloznikov AA (2018) TNF $\alpha$-induced expression of transport protein genes in HUVEC cells is associated with enhanced expression of transcription factor genes RELB and NFKB2 of the non-canonical NF-кB pathway. Bull Exp Biol Med 164: $757-761$.

Kobayashi M, Otsuka Y, Itagaki S, Hirano T, and Iseki K (2006) Inhibitory effects of statins on human monocarboxylate transporter 4. Int J Pharm 317:19-25.

Kohyama N, Shiokawa H, Ohbayashi M, Kobayashi Y, and Yamamoto T (2013) Characterization of monocarboxylate transporter 6: expression in human intestine and transport of the antidiabetic drug nateglinide. Drug Metab Dispos 41 1883-1887.

König B, Fischer S, Schlotte S, Wen G, Eder K, and Stangl GI (2010) Monocarboxylate transporter 1 and CD147 are up-regulated by natural and synthetic peroxisome proliferator-activated receptor alpha agonists in livers of rodents and pigs. Mol Nutr Food Res 54:1248-1256.

König B, Koch A, Giggel K, Dordschbal B, Eder K, and Stangl GI (2008) Monocarboxylate transporter (MCT)-1 is up-regulated by PPARalpha. Biochim Biophys Acta 1780:899-904.

Krishnan MN, Ng A, Sukumaran B, Gilfoy FD, Uchil PD, Sultana H, Brass AL Adametz R, Tsui M, Qian F, et al. (2008) RNA interference screen for human genes associated with West Nile virus infection. Nature 455:242-245.

Lake AD, Novak P, Shipkova P, Aranibar N, Robertson DG, Reily MD, LehmanMcKeeman LD, Vaillancourt RR, and Cherrington NJ (2015) Branched chain amino acid metabolism profiles in progressive human nonalcoholic fatty liver disease. Amino Acids 47:603-615

Lengacher S, Nehiri-Sitayeb T, Steiner N, Carneiro L, Favrod C, Preitner F, Thorens B, Stehle JC, Dix L, Pralong F, et al. (2013) Resistance to diet-induced obesity and associated metabolic perturbations in haploinsufficient monocarboxylate transporter 1 mice. PLoS One 8:e82505.

Li KK, Pang JC, Ching AK, Wong CK, Kong X, Wang Y, Zhou L, Chen Z, and Ng HK (2009) miR-124 is frequently down-regulated in medulloblastoma and is a negative regulator of SLC16A1. Hum Pathol 40:1234-1243.

Liang D, Zhang Y, Han J, Wang W, Liu Y, Li J, and Jiang X (2015) Embryonic stem cell-derived pancreatic endoderm transplant with MCT1-suppressing miR-495 attenuates type II diabetes in mice. Endocr J 62:907-920.

Lin RY, Vera JC, Chaganti RS, and Golde DW (1998) Human monocarboxylate transporter 2 (MCT2) is a high affinity pyruvate transporter. $J$ Biol Chem $\mathbf{2 7 3}$ 28959-28965.

Lin WR, Chiang JM, Lim SN, Su MY, Chen TH, Huang SW, Chen CW, Wu RC, Tsai CL, Lin YH, et al. (2019) Dynamic bioenergetic alterations in colorectal adenomatous polyps and adenocarcinomas. EBioMedicine 44:334-345.

Liu J, Zhou Y, Liu S, Song X, Yang XZ, Fan Y, Chen W, Akdemir ZC, Yan Z, Zuo Y, et al.; DISCO (Deciphering Disorders Involving Scoliosis and COmorbidities) Study (2018) The coexistence of copy number variations (CNVs) and single nucleotide 
polymorphisms (SNPs) at a locus can result in distorted calculations of the significance in associating SNPs to disease. Hum Genet 137:553-567.

Luo F, Zou Z, Liu X, Ling M, Wang Q, Wang Q, Lu L, Shi L, Liu Y, Liu Q, et al. (2017) Enhanced glycolysis, regulated by HIF-1 $\alpha$ via MCT-4, promotes inflammation in arsenite-induced carcinogenesis. Carcinogenesis 38:615-626.

Manning Fox JE, Meredith D, and Halestrap AP (2000) Characterisation of human monocarboxylate transporter 4 substantiates its role in lactic acid efflux from skeletal muscle. J Physiol 529:285-293.

Marchiq I and Pouysségur J (2016) Hypoxia, cancer metabolism and the therapeutic benefit of targeting lactate/H(+) symporters. J Mol Med (Berl) 94:155-171.

Mariotta L, Ramadan T, Singer D, Guetg A, Herzog B, Stoeger C, Palacín M, Lahoutte T, Camargo SM, and Verrey F (2012) T-type amino acid transporter TAT1 (Slc16a10) is essential for extracellular aromatic amino acid homeostasis control. J Physiol 590:6413-6424.

Martins AD, Alves MG, Simões VL, Dias TR, Rato L, Moreira PI, Socorro S, Cavaco JE, and Oliveira PF (2013) Control of sertoli cell metabolism by sex steroid hormones is mediated through modulation in glycolysis-related transporters and enzymes. Cell Tissue Res 354:861-868.

Mayerl S, Müller J, Bauer R, Richert S, Kassmann CM, Darras VM, Buder K, Boelen A, Visser TJ, and Heuer H (2014) Transporters MCT8 and OATP1C1 maintain murine brain thyroid hormone homeostasis. J Clin Invest 124:1987-1999.

Mboge MY, Chen Z, Khokhar D, Wolff A, Ai L, Heldermon CD, Bozdag M, Carta F, Supuran CT, Brown KD, et al. (2019) A non-catalytic function of carbonic anhydrase IX contributes to the glycolytic phenotype and $\mathrm{pH}$ regulation in human breast cancer cells. Biochem J 476:1497-1513.

McClintick JN, Tischfield JA, Deng L, Kapoor M, Xuei X, and Edenberg HJ (2019) Ethanol activates immune response in lymphoblastoid cells. Alcohol 79:81-91.

Miranda-Lora AL, Cruz M, Molina-Díaz M, Gutiérrez J, Flores-Huerta S and Klünder-Klünder M (2017) Associations of common variants in the SLC16A11, TCF7L2, and ABCA1 genes with pediatric-onset type 2 diabetes and related glycemic traits in families: a case-control and case-parent trio study. Pediatr Diabetes 18:824-831.

Mooij MG, Nies AT, Knibbe CA, Schaeffeler E, Tibboel D, Schwab M, and de Wildt SN (2016) Development of human membrane transporters: drug disposition and pharmacogenetics. Clin Pharmacokinet 55:507-524.

Morris ME and Felmlee MA (2008) Overview of the proton-coupled MCT (SLC16A) family of transporters: characterization, function and role in the transport of the drug of abuse gamma-hydroxybutyric acid. AAPS $J$ 10:311-321.

Morse BL, Felmlee MA, and Morris ME (2012) $\gamma$-Hydroxybutyrate blood/plasma partitioning: effect of physiologic $\mathrm{pH}$ on transport by monocarboxylate transporters. Drug Metab Dispos 40:64-69.

Mowbray J (1974) Evidence for the role of a specific monocarboxylate transporter in the control of pyruvate oxidation by rat liver mitochondria. FEBS Lett 44:344-347.

Mowbray J (1975) A mitochondrial monocarboxylate transporter in rat liver and heart and its possible function in cell control. Biochem $J$ 148:41-47.

Müller J, Mayerl S, Visser TJ, Darras VM, Boelen A, Frappart L, Mariotta L, Verrey F, and Heuer H (2014) Tissue-specific alterations in thyroid hormone homeostasis in combined Mct10 and Mct8 deficiency. Endocrinology 155:315-325.

Murakami Y, Kohyama N, Kobayashi Y, Ohbayashi M, Ohtani H, Sawada Y, and Yamamoto T (2005) Functional characterization of human monocarboxylate transporter 6 (SLC16A5). Drug Metab Dispos 33:1845-1851.

Nakai M, Chen L, and Nowak RA (2006) Tissue distribution of basigin and monocarboxylate transporter 1 in the adult male mouse: a study using the wild-type and basigin gene knockout mice. Anat Rec A Discov Mol Cell Evol Biol 288:527-535.

Nancolas B, Guo L, Zhou R, Nath K, Nelson DS, Leeper DB, Blair IA, Glickson JD, and Halestrap AP (2016) The anti-tumour agent lonidamine is a potent inhibitor of the mitochondrial pyruvate carrier and plasma membrane monocarboxylate transporters. Biochem J 473:929-936.

Narumi K, Kobayashi M, Otake S, Furugen A, Takahashi N, Ogura J, Itagaki S, Hirano T, Yamaguchi H, and Iseki K (2012) Regulation of human monocarboxylate transporter 4 in skeletal muscle cells: the role of protein kinase $\mathrm{C}$ (PKC). Int $J$ Pharm 428:25-32.

Nishimura M and Naito S (2008) Tissue-specific mRNA expression profiles of human solute carrier transporter superfamilies. Drug Metab Pharmacokinet 23:22-44.

Noble RA, Bell N, Blair H, Sikka A, Thomas H, Phillips N, Nakjang S, Miwa S, Crossland R, Rand V, et al. (2017) Inhibition of monocarboxyate transporter 1 by AZD3965 as a novel therapeutic approach for diffuse large B-cell lymphoma and Burkitt lymphoma. Haematologica 102:1247-1257.

Noor SI, Dietz S, Heidtmann H, Boone CD, McKenna R, Deitmer JW, and Becker HM (2015) Analysis of the binding moiety mediating the interaction between monocarboxylate transporters and carbonic anhydrase II. J Biol Chem 290:4476-4486.

Noor SI, Jamali S, Ames S, Langer S, Deitmer JW, and Becker HM (2018) A surface proton antenna in carbonic anhydrase II supports lactate transport in cancer cells. Life 7:e35176.

Noor SI, Pouyssegur J, Deitmer JW, and Becker HM (2017) Integration of a 'proton antenna' facilitates transport activity of the monocarboxylate transporter MCT4. FEBS J 284:149-162.

Novara F, Groeneweg S, Freri E, Estienne M, Reho P, Matricardi S, Castellotti B Visser WE, Zuffardi O, and Visser TJ (2017) Clinical and molecular characteristics of SLC16A2 (MCT8) mutations in three families with the Allan-Herndon-Dudley syndrome. Hum Mutat 38:260-264.

Onali F, Calò CM, Massidda M, Álvarez-Álvarez MM, and Esteban ME (2018) An unexpected world population variation of MCT1 polymorphism 1470T $>$ A involved in lactate transport. Eur J Sport Sci 18:1376-1382.

Otonkoski T, Jiao H, Kaminen-Ahola N, Tapia-Paez I, Ullah MS, Parton LE, Schuit F, Quintens R, Sipilä I, Mayatepek E, et al. (2007) Physical exercise-induced hypoglycemia caused by failed silencing of monocarboxylate transporter 1 in pancreatic beta cells. Am J Hum Genet 81:467-474

Ovens MJ, Manoharan C, Wilson MC, Murray CM, and Halestrap AP (2010) The inhibition of monocarboxylate transporter 2 (MCT2) by AR-C155858 is modulated by the associated ancillary protein. Biochem J 431:217-225.
Park SJ, Smith CP, Wilbur RR, Cain CP, Kallu SR, Valasapalli S, Sahoo A, Guda MR, Tsung AJ, and Velpula KK (2018) An overview of MCT1 and MCT4 in GBM: small molecule transporters with large implications. Am $J$ Cancer Res 8: 1967-1976.

Pellerin L, Pellegri G, Martin JL, and Magistretti PJ (1998) Expression of monocarboxylate transporter mRNAs in mouse brain: support for a distinct role of lactate as an energy substrate for the neonatal vs. adult brain. Proc Natl Acad Sci USA 95:3990-3995.

Pérez-Escuredo J, Van Hée VF, Sboarina M, Falces J, Payen VL, Pellerin L, and Sonveaux P (2016) Monocarboxylate transporters in the brain and in cancer. Biochim Biophys Acta 1863:2481-2497.

Pértega-Gomes N, Vizcaíno JR, Gouveia C, Jerónimo C, Henrique RM, Lopes C, and Baltazar F (2013) Monocarboxylate transporter 2 (MCT2) as putative biomarker in prostate cancer. Prostate 73:763-769.

Philp NJ, Wang D, Yoon H, and Hjelmeland LM (2003) Polarized expression of monocarboxylate transporters in human retinal pigment epithelium and ARPE-19 cells. Invest Ophthalmol Vis Sci 44:1716-1721.

Philp NJ, Yoon H, and Lombardi L (2001) Mouse MCT3 gene is expressed preferentially in retinal pigment and choroid plexus epithelia. Am J Physiol Cell Physiol 280:C1319-C1326.

Pinheiro C, Longatto-Filho A, Azevedo-Silva J, Casal M, Schmitt FC, and Baltazar F (2012) Role of monocarboxylate transporters in human cancers: state of the art. J Bioenerg Biomembr 44:127-139.

Pinheiro C, Reis RM, Ricardo S, Longatto-Filho A, Schmitt F, and Baltazar F (2010) Expression of monocarboxylate transporters 1,2, and 4 in human tumours and their association with CD147 and CD44. J Biomed Biotechnol 2010:427694.

Polański R, Hodgkinson CL, Fusi A, Nonaka D, Priest L, Kelly P, Trapani F, Bishop PW, White A, Critchlow SE, et al. (2014) Activity of the monocarboxylate transporter 1 inhibitor AZD3965 in small cell lung cancer. Clin Cancer Res 20:926-937.

Poole RC and Halestrap AP (1994) N-terminal protein sequence analysis of the rabbit erythrocyte lactate transporter suggests identity with the cloned monocarboxylate transport protein MCT1. Biochem J 303:755-759.

Poole RC and Halestrap AP (1997) Interaction of the erythrocyte lactate transporter (monocarboxylate transporter 1 ) with an integral $70-\mathrm{kDa}$ membrane glycoprotein of the immunoglobulin superfamily. J Biol Chem 272:14624-14628.

Price NT, Jackson VN, and Halestrap AP (1998) Cloning and sequencing of four new mammalian monocarboxylate transporter (MCT) homologues confirms the existence of a transporter family with an ancient past. Biochem $J$ 329:321-328.

Pullen TJ, da Silva Xavier G, Kelsey G, and Rutter GA (2011) miR-29a and miR-29b contribute to pancreatic beta-cell-specific silencing of monocarboxylate transporter 1 (Mct1). Mol Cell Biol 31:3182-3194.

Rato L, Alves MG, Socorro S, Carvalho RA, Cavaco JE, and Oliveira PF (2012) Metabolic modulation induced by oestradiol and DHT in immature rat Sertoli cells cultured in vitro. Biosci Rep 32:61-69.

Roberts LM, Woodford K, Zhou M, Black DS, Haggerty JE, Tate EH, Grindstaff KK, Mengesha W, Raman C, and Zerangue N (2008) Expression of the thyroid hormone transporters monocarboxylate transporter-8 (SLC16A2) and organic ion transporter-14 (SLCO1C1) at the blood-brain barrier. Endocrinology 149: 6251-6261.

Römermann K, Fedrowitz M, Hampel P, Kaczmarek E, Töllner K, Erker T, Sweet DH, and Löscher W (2017) Multiple blood-brain barrier transport mechanism limit bumetanide accumulation, and therapeutic potential, in the mammalian brain. Neuropharmacology 117:182-194.

Roshanbin S, Lindberg FA, Lekholm E, Eriksson MM, Perland E, Åhlund J, Raine A, and Fredriksson R (2016) Histological characterization of orphan transporter MCT14 (SLC16A14) shows abundant expression in mouse CNS and kidney. BMC Neurosci 17:43.

Rusu V, Hoch E, Mercader JM, Tenen DE, Gymrek M, Hartigan CR, DeRan M, von Grotthuss M, Fontanillas P, Spooner A, et al. (2017) Type 2 diabetes variants disrupt function of SLC16A11 through two distinct mechanisms. Cell $\mathbf{1 7 0}$ 199-212.e20.

Saksena S, Dwivedi A, Gill RK, Singla A, Alrefai WA, Malakooti J, Ramaswamy K, and Dudeja PK (2009) PKC-dependent stimulation of the human MCT1 promoter involves transcription factor AP2. Am J Physiol Gastrointest Liver Physiol 296 G275-G283.

Schwartz CE, May MM, Carpenter NJ, Rogers RC, Martin J, Bialer MG, Ward J, Sanabria J, Marsa S, Lewis JA, et al. (2005) Allan-Herndon-Dudley syndrome and the monocarboxylate transporter 8 (MCT8) gene. Am J Hum Genet 77:41-53.

Settle P, Mynett K, Speake P, Champion E, Doughty IM, Sibley CP, D’Souza SW, and Glazier J (2004) Polarized lactate transporter activity and expression in the syncytiotrophoblast of the term human placenta. Placenta 25:496-504.

Sharlin DS, Ng L, Verrey F, Visser TJ, Liu Y, Olszewski RT, Hoa M, Heuer H, and Forrest D (2018) Deafness and loss of cochlear hair cells in the absence of thyroid hormone transporters Slc16a2 (Mct8) and Slc16a10 (Mct10). Sci Rep 8:4403.

Shen C, Chen R, Qian Z, Meng X, Hu T, Li Y, Chen Z, Huang C, Hu C, and Li J (2015) Intestinal absorption mechanisms of MTBH, a novel hesperetin derivative, in Caco-2 cells, and potential involvement of monocarboxylate transporter 1 and multidrug resistance protein 2. Eur J Pharm Sci 78:214-224.

Stäubli A, Capatina N, Fuhrer Y, Munier FL, Labs S, Schorderet DF, Tiwari A Verrey F, Heon E, Cheng CY, et al. (2017) Abnormal creatine transport of mutations in monocarboxylate transporter 12 (MCT12) found in patients with agerelated cataract can be partially rescued by exogenous chaperone CD147. Hum Mol Genet 26:4203-4214.

Stohn JP, Martinez ME, Matoin K, Morte B, Bernal J, Galton VA, St Germain D, and Hernandez A (2016) MCT8 deficiency in male mice mitigates the phenotypic abnormalities associated with the absence of a functional type 3 deiodinase. En docrinology 157:3266-3277.

Sugito K, Kawashima H, Uekusa S, Yoshizawa S, Hoshi R, Furuya T, Kaneda H, Hosoda T, Masuko T, Ohashi K, et al. (2013) Identification of aberrant methylation regions in neuroblastoma by screening of tissue-specific differentially methylated regions. Pediatr Blood Cancer 60:383-389. 
Suhre K, Shin SY, Petersen AK, Mohney RP, Meredith D, Wägele B, Altmaier E, Deloukas P, Erdmann J, Grundberg E, et al ; CARDIoGRAM (2011) Human metabolic individuality in biomedical and pharmaceutical research. Nature 477:54-60

Tadi M, Allaman I, Lengacher S, Grenningloh G, and Magistretti PJ (2015) Learninginduced gene expression in the Hippocampus reveals a role of neuron-astrocyte metabolic coupling in long term memory. PLoS One 10:e0141568.

Takimoto M, Takeyama M, and Hamada T (2013) Possible involvement of AMPK in acute exercise-induced expression of monocarboxylate transporters MCT1 and MCT4 mRNA in fast-twitch skeletal muscle. Metabolism 62:1633-1640.

Trajkovic M, Visser TJ, Mittag J, Horn S, Lukas J, Darras VM, Raivich G, Bauer K and Heuer H (2007) Abnormal thyroid hormone metabolism in mice lacking the monocarboxylate transporter 8. J Clin Invest 117:627-635.

Ullah MS, Davies AJ, and Halestrap AP (2006) The plasma membrane lactate transporter MCT4, but not MCT1, is up-regulated by hypoxia through a HIF-1alpha-dependent mechanism. J Biol Chem 281:9030-9037.

van der Deure WM, Peeters RP, and Visser TJ (2007) Genetic variation in thyroid hormone transporters. Best Pract Res Clin Endocrinol Metab 21:339-350.

van Groen BD, van de Steeg E, Mooij MG, van Lipzig MMH, de Koning BAE, Verdijk RM, Wortelboer HM, Gaedigk R, Bi C, Leeder JS, et al. (2018) Proteomics of human liver membrane transporters: a focus on fetuses and newborn infants. Eur J Pharm Sci 124:217-227.

Vannucci SJ and Simpson IA (2003) Developmental switch in brain nutrient transporter expression in the rat. Am J Physiol Endocrinol Metab 285:E1127-E1134.

Vijay N and Morris ME (2014) Role of monocarboxylate transporters in drug delivery to the brain. Curr Pharm Des 20:1487-1498.

Wang C, Wen Z, Xie J, Zhao Y, Zhao L, Zhang S, Liu Y, Xue Y, and Shi M (2017) MACC1 mediates chemotherapy sensitivity of 5-FU and cisplatin via regulating MCT1 expression in gastric cancer. Biochem Biophys Res Commun 485:665-671.

Wang Q, Darling IM, and Morris ME (2006a) Transport of gamma-hydroxybutyrate in rat kidney membrane vesicles: role of monocarboxylate transporters. J Pharmacol Exp Ther 318:751-761.

Wang Q, Lu Y, Yuan M, Darling IM, Repasky EA, and Morris ME (2006b) Characterization of monocarboxylate transport in human kidney HK-2 cells. Mol Pharm 3: 675-685.

Wang Y, Guo SZ, Bonen A, Li RC, Kheirandish-Gozal L, Zhang SX, Brittian KR and Gozal D (2011) Monocarboxylate transporter 2 and stroke severity in a rodent model of sleep apnea. $J$ Neurosci 31:10241-10248.

Wei CJ, Cui P, Li H, Lang WJ, Liu GY, and Ma XF (2019) Shared genes between Alzheimer's disease and ischemic stroke. CNS Neurosci Ther 25:855-864.

Williams AL, Jacobs SB, Moreno-Macías H, Huerta-Chagoya A, Churchhouse C, Márquez-Luna C, García-Ortíz H, Gómez-Vázquez MJ, Burtt NP, Aguilar-Salinas CA et al.; SIGMA Type 2 Diabetes Consortium (2014) Sequence variants in SLC16A11 are a common risk factor for type 2 diabetes in Mexico. Nature 506:97-101.
Wilson MC, Kraus M, Marzban H, Sarna JR, Wang Y, Hawkes R, Halestrap AP, and Beesley PW (2013) The neuroplastin adhesion molecules are accessory proteins that chaperone the monocarboxylate transporter MCT2 to the neuronal cell surface. PLoS One 8:e78654

Wilson MC, Meredith D, Bunnun C, Sessions RB, and Halestrap AP (2009) Studies on the DIDS-binding site of monocarboxylate transporter 1 suggest a homology model of the open conformation and a plausible translocation cycle. $J$ Biol Chem 284:20011-20021.

Wilson MC, Meredith D, Fox JE, Manoharan C, Davies AJ, and Halestrap AP (2005) Basigin (CD147) is the target for organomercurial inhibition of monocarboxylate transporter isoforms 1 and 4: the ancillary protein for the insensitive MCT2 is EMBIGIN (gp70). J Biol Chem 280:27213-27221.

Wilson MC, Meredith D, and Halestrap AP (2002) Fluorescence resonance energy transfer studies on the interaction between the lactate transporter MCT1 and CD147 provide information on the topology and stoichiometry of the complex in situ. J Biol Chem 277:3666-3672.

Wirth EK, Roth S, Blechschmidt C, Hölter SM, Becker L, Racz I, Zimmer A, Klopstock T, Gailus-Durner V, Fuchs H, et al. (2009) Neuronal 3',3,5-triiodothyronine (T3) uptake and behavioral phenotype of mice deficient in Mct8, the neuronal T3 transporter mutated in Allan-Herndon-Dudley syndrome. $J$ Neurosci 29: 9439-9449.

Xu W, Zhang Z, Zou K, Cheng Y, Yang M, Chen H, Wang H, Zhao J, Chen P, He L, et al. (2017) MiR-1 suppresses tumor cell proliferation in colorectal cancer by inhibition of Smad3-mediated tumor glycolysis. Cell Death Dis 8:e2761.

Yan P, Li YH, Tang ZJ, Shu X, and Liu X (2014) High monocarboxylate transporter 4 protein expression in stromal cells predicts adverse survival in gastric cancer Asian Pac J Cancer Prev 15:8923-8929.

Yoon H, Fanelli A, Grollman EF, and Philp NJ (1997) Identification of a unique monocarboxylate transporter (MCT3) in retinal pigment epithelium. Biochem Biophys Res Commun 234:90-94.

Ždralević M, Vučetić M, Daher B, Marchiq I, Parks SK, and Pouysségur J (2018) Disrupting the 'Warburg effect' re-routes cancer cells to OXPHOS offering a vulnerability point via 'ferroptosis'-induced cell death. Adv Biol Regul 68:55-63.

Zhao Y, Feng Z, Zhang Y, Sun Y, Chen Y, Liu X, Li S, Zhou T, Chen L, Wei Y, et al. (2019) Gain-of-function mutations of SLC16A11 contribute to the pathogenesis of type 2 diabetes. Cell Rep 26:884-892.e4.

Zhu S, Goldschmidt-Clermont PJ, and Dong C (2005) Inactivation of monocarboxylate transporter MCT3 by DNA methylation in atherosclerosis. Circulation 112:1353-1361.

Zuercher J, Neidhardt J, Magyar I, Labs S, Moore AT, Tanner FC, Waseem N, Schorderet DF, Munier FL, Bhattacharya S, et al. (2010) Alterations of the 5'untranslated region of SLC16A12 lead to age-related cataract. Invest Ophthalmol Vis Sci 51:3354-3361. 